\title{
Chemosphere
}

October 2018, Voulume 209, Pages 801-814

http://dx.doi.org/10.1016/i.chemosphere.2018.06.139

http://archimer.ifremer.fr/doc/00445/55695/

(c) 2018 Elsevier Ltd. All rights reserved.

\section{Combined effects of antifouling biocides on the growth of three marine microalgal species}

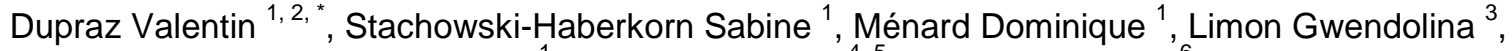 \\ Akcha Farida ${ }^{1}$, Budzinski Hélène ${ }^{4,5}$, Cedergreen Nina ${ }^{6}$
}

${ }^{1}$ Ifremer, Laboratoire d'Écotoxicologie, rue de l'île d'Yeu, BP 21105, F-44311, Nantes Cedex 03, France

${ }^{2}$ Université de Nantes, UFR Sciences et Techniques, 2, rue de la Houssinière, BP 92208, 44322,

Nantes Cedex 03, France

${ }^{3}$ LABOCEA, Unité R\&D, 120 Avenue de Rochon, 29280, Plouzané, France

${ }^{4}$ Université de Bordeaux, UMR 5805, EPOC, Laboratoire de Physico Toxico Chimie de

l'environnement, 351 Cours de la Libération, CS 10004, F-33405, Talence Cedex, France

${ }^{5}$ CNRS, UMR 5805, EPOC, Laboratoire de Physico Toxico Chimie de l'environnement, 351 Cours de la Libération, CS 10004, F-33405, Talence Cedex, France

${ }^{6}$ Department of Plant and Environmental Sciences, University of Copenhagen, Frederiksberg, Denmark

*Corresponding author : Valentin Dupraz, email address : valentin.dupraz@ifremer.fr

\begin{abstract}
:
The toxicity of the antifouling compounds diuron, irgarol, zinc pyrithione ( $\mathrm{ZnPT}$ ), copper pyrithione (CuPT) and copper was tested on the three marine microalgae Tisochrysis lutea, Skeletonema marinoi and Tetraselmis suecica. Toxicity tests based on the inhibition of growth rate after 96-h exposure were run using microplates. Chemical analyses were performed to validate the exposure concentrations and the stability of the compounds under test conditions.

Single chemicals exhibited varying toxicity depending on the species, irgarol being the most toxic chemical and $\mathrm{Cu}$ the least toxic. Selected binary mixtures were tested and the resulting interactions were analyzed using two distinct concentration-response surface models: one using the concentration addition (CA) model as reference and two deviating isobole models implemented in $\mathrm{R}$ software; the other implementing concentration-response surface models in Excel ${ }^{\circledR}$, using both $\mathrm{CA}$ and independent action (IA) models as reference and three deviating models. Most mixtures of chemicals sharing the same mode of action (MoA) were correctly predicted by the CA model. For mixtures of dissimilarly acting chemicals, neither of the reference models provided better predictions than the other. Mixture of $\mathrm{ZnPT}$ together with $\mathrm{Cu}$ induced a strong synergistic effect on $\mathrm{T}$. suecica while strong antagonism was observed on the two other species. The synergy was due to the transchelation of ZnPT into CuPT in the presence of $\mathrm{Cu}$, CuPT being 14-fold more toxic than ZnPT for this species. The two modelling approaches are compared and the differences observed among the interaction patterns resulting from the mixtures are discussed.
\end{abstract}




\section{Highlight}

- The toxicity of antifouling binary mixtures was tested on three microalgae species. Both methods used to predict interactive effects of mixtures gave similar results. Mixtures of similarly acting chemicals were close to the CA model predictions. Mixture of $\mathrm{ZnPT}$ and $\mathrm{Cu}$ induced strong synergism on Tetraselmis suecica. - Transchelation of ZnPT into CuPT in presence of $\mathrm{Cu}^{2+}$ was demonstrated.

Keywords : Diuron, Irgarol, Pyrithione, Copper, Microbial ecotoxicology, Mixture model 


\section{$44 \quad 1$ Introduction}

45 Diuron (1-(3,4 dichlorophenyl)-3,3 dimethyl urea), irgarol (2-methylthio-4-tertbutylamino-6-

46 cyclopropylamino-s-triazine), Zinc Pyrithione and Copper Pyrithione (ZnPT/CuPT, bis(2-

47 pyridylthio)zinc/copper 1,1'-dioxide) are among the proposed chemicals to be used as "booster"

48 biocides in Cu-based antifouling paints (Konstantinou and Albanis, 2004). These biocides are usually

49 used alone, in combination with $\mathrm{Cu}$, although two can co-occur in some paint formulations

50 (Environment Agency, 1998). Leaching of these substances to the environment occurs directly from

51 both the ship hull (Readman et al., 1993; Takahashi, 2009) and the discarded antifouling paint

52 particles (Turner et al., 2008; Turner, 2010; Hasan et al., 2014), especially during maintenance and

53 cleaning (Links et al., 2006).

54 Recently, the use of diuron (Regulation (EU) No 528/2012) and irgarol (Regulation (EU) No 2016/107)

55 as biocides has been prohibited in Europe because of their high toxicity towards aquatic life and both

56 have been included in the list of " 48 priority pollutants to be monitored in European waters" in the

57 Water Framework Directive (2000/60/EC and 2013/39/EU). Nonetheless, diuron and irgarol are still

58 found in European fresh and coastal waters. Concentrations up to $0.27 \mu \mathrm{g} \mathrm{L}^{-1}$ diuron and $0.19 \mu \mathrm{g} \mathrm{L}^{-1}$ 
irgarol were reported by Caquet et al. (2013) in Vilaine Bay (Brittany, France) and even higher concentrations up to $2.60 \mu \mathrm{g} \mathrm{L}^{-1}$ diuron and $0.82 \mu \mathrm{g} \mathrm{L}^{-1}$ irgarol were reported in careening areas of several French ports (Cozic and Durand, 2013). Diuron (phenylurea) and irgarol (S-triazine) both act as photosystem II (PSII) inhibitors by competing with the quinone $Q_{B}$ on its binding site located in the D1 protein, thus preventing electron transfer between $Q_{A}$ and $Q_{B}$ and inhibiting Hill's reaction (Nimbal et al., 1996; Jones and Kerswell, 2003). Several studies reported the high toxicity of these compounds towards microalgae: Koutsaftis and Aoyama (2006) determined 72-h 50\% inhibitory concentrations (IC50) of 36.0 and $1.10 \mu \mathrm{g} \mathrm{L}^{-1}$ on the growth of the diatom Chaetoceros gracilis for diuron and irgarol, respectively. Bao et al. (2011) reported 96-h EC50 values for diuron and irgarol of 5.90 and $0.57 \mu \mathrm{g} \mathrm{L}{ }^{-}$ ${ }^{1}$, and 4.30 and $0.39 \mu \mathrm{g} \mathrm{L}^{-1}$ on the growth of the marine microalgae Skeletonema costatum and Thalassiosira pseudonana, respectively.

On contrary to diuron and irgarol, very little is known about the occurrence of the two organometals ZnPT and CuPT in the environment. Indeed, literature about pyrithione concentrations in water is very scarce: to our knowledge, only one study reported the occurrence of pyrithione (PT, Hydroxy-2(1H)pyridinethione) in the marine environment, at a concentration of $13.4 \pm 0.60 \mu \mathrm{g} \mathrm{L}^{-1}$ measured by cathodic stripping voltammetry in a marina from Mersey estuary (United Kingdom) (Mackie et al., 2004). ZnPT and CuPT usually co-occur in the marine environment as they are both present in antifouling paints, and because ZnPT easily transchelates into CuPT in presence of $\mathrm{Cu}$ (Thomas, 1999; Maraldo and Dahllöf, 2004; Grunnet and Dahllöf, 2005). ZnPT has long been used for its bactericidal and fungicidal activity, especially in antidandruff shampoos (Yebra et al., 2004), and has been proposed as one of the most relevant compounds to replace TBT in antifouling paints during the past decade (Doose et al., 2004). It is assumed to act by disrupting cell membrane integrity and inhibiting ATP synthesis and membrane transport (Chandler and Segel, 1978; Dinning et al., 1998b, 1998a). No study specifically evaluated the mode of action (MoA) of CuPT, though it is reasonable to think that it shares the same mechanism as ZnPT. Regarding their toxicity on microalgae, Yamada (2006) reported 72-h EC50 of 2.10 and $28.4 \mu \mathrm{g} \mathrm{L}^{-1}$ on the growth of S. costatum, and 28.0 and $35.0 \mu \mathrm{g}$ $\mathrm{L}^{-1}$ on the growth of Selenastrum capricornutum, for ZnPT and CuPT, respectively. In another study on S. costatum, the 72-h EC50 were 1.60 and $1.50 \mu \mathrm{g} \mathrm{L}^{-1}$ for ZnPT and CuPT (Onduka et al., 2010), while Devilla et al. (2005) determined a 72-h EC50 of $0.54 \mu \mathrm{g} \mathrm{L}^{-1}$ for ZnPT on the growth of the microalga Emiliania huxleyi. 
Concerning copper, since its bioavailable form is the dissolved ionic form $\mathrm{Cu}^{2+}$, the abbreviation $\mathrm{Cu}$ will refer to $\mathrm{Cu}^{2+}$ ions throughout this article. Most antifouling paints contain copper in the form of copper (I) oxide (or cuprous oxide, $\mathrm{Cu}_{2} \mathrm{O}$ ), or more rarely copper(I)thiocyanate (or cuprous thiocyanate, CuSCN). Once in seawater, $\mathrm{Cu}_{2} \mathrm{O}$ and $\mathrm{CuSCN}$ are oxidized in $\mathrm{Cu}^{2+}$ (Vetere et al., 1997). As a result, marinas, coastal and estuarine waters are often contaminated by elevated concentrations of $\mathrm{Cu}$ in sediments and surface waters. Average dissolved $\mathrm{Cu}$ concentrations of 8.50 and $11.2 \mu \mathrm{g} \mathrm{L}^{-1}$ have been reported in marinas of the San Diego region (USA) (Schiff et al., 2007) and beach waters in Acapulco (Mexico) (Jonathan et al., 2011), respectively. $\mathrm{Cu}$ is an essential component in many metabolic processes in microalgae, however, concentrations above the optimum level can become toxic (Baron et al., 1995). Toxic MoA of $\mathrm{Cu}$ is thought to inhibit electron transport by damaging acceptor and donor sides of the PSII (Patsikka et al., 1998), hence decreasing the photosynthetic efficiency (El Berdey et al., 2000). Regarding its toxicity towards microalgae, a 96-h EC50 of $970 \mu \mathrm{g} \mathrm{L}{ }^{-}$ ${ }^{1}$ was reported by Bao et al. (2008) on the growth of the microalgae Thalassiosira pseudonana, while Koutsaftis and Aoyama (2006) determined a 72-h IC50 of $1200 \mathrm{\mu g} \mathrm{L}^{-1}$ on the growth of Chaetoceros gracilis.

Numerous studies have shown the importance of studying mixtures of chemicals, as it is more environmentally relevant and because chemicals in mixtures can exhibit higher toxicity than they would alone (Fernandez-Alba et al., 2002; Franklin et al., 2002; Cedergreen et al., 2006; Koutsaftis and Aoyama, 2006). Cedergreen (2014) reported that approximately $5 \%$ of the tested pesticide mixtures exhibit larger effects than predicted, while for antifouling mixtures it was approximately $26 \%$ of the tested mixtures. Two main reference models are used to predict the toxicity of mixtures. The most frequently used is the concentration addition (CA) model, also referred as Loewe additivity (Loewe and Muischnek, 1926), which is based on the assumption that chemicals sharing the same molecular target can thus be considered as dilutions of each other. On the contrary, the independent action (IA) model considers that chemicals acting on independent targets can result in a binary response: either affected or non-affected. Hence, the probability of surviving a mixture following IA is equal to the product of the probabilities of surviving each of the chemicals individually. Several other models (Hewlett, 1969; Vølund, 1992; Jonker et al., 2005) describe types of deviations from these two reference models, being either synergistic (greater effect than predicted), antagonistic (smaller effect than predicted) or a mixture of the two. 
Phytoplankton is responsible for over half of the global annual primary production on earth (Beardall and Raven, 2016) and occupies a key role in the oceanic food web. As many phytoplankton species are living in marinas and harbor areas, they are exposed to cocktails of chemicals, especially antifouling biocides. In this study, binary mixtures of antifouling biocides (including $\mathrm{Cu}$ ) were tested on three marine microalgal species: the haptophyte Tisochrysis lutea, the diatom Skeletonema marinoi and the chlorophyte Tetraselmis suecica.

To evaluate the extent to which the combined toxicity of antifouling biocides together with $\mathrm{Cu}$ can harm marine microalgae, the goals of this study were: i) to determine the toxicity of diuron, irgarol, $\mathrm{ZnPT}$, CuPT and $\mathrm{Cu}$ on the three species of microalgae; and ii) to evaluate and compare the interaction patterns of six chosen binary mixtures through two different modelling approaches testing deviations from the CA and IA models.

\section{Materials and methods}

\subsection{Chemical / toxicant preparation}

Diuron, irgaro| $\circledast$, (PESTANAL $\Theta$, analytical standard), Zinc Pyrithione (ZnPT) and copper(II) sulfate pentahydrate $\left(\mathrm{CuSO}_{4}, \geq 98 \%\right)$ were purchased from Sigma-Aldrich. Copper Pyrithione (CuPT) was purchased from Santa Cruz Biotechnology. Internal standards diuron-d6 and irgarol-d9 were purchased from Cluzeau Info Labo (Sainte Foy la Grande, France). Stock solutions of irgarol $\left(0.57 \mathrm{~g} \mathrm{~L}^{-}\right.$ $\left.{ }^{1}\right)$, diuron (1.04 $\left.\mathrm{g} \mathrm{L}^{-1}\right)$, ZnPT $\left(0.51 \mathrm{~g} \mathrm{~L}^{-1}\right)$ and CuPT $\left(0.49 \mathrm{~g} \mathrm{~L}^{-1}\right)$ were prepared in pure DMSO $(\geq 99 \%)$ and stock solution of $\mathrm{CuSO}_{4}\left(3.20 \mathrm{~g} \mathrm{~L}^{-1}\right)$ was prepared in sterile ultra-pure water. All stock solutions were analyzed to ensure their concentrations (2.4; Table 2 and supplementary data Table S3). Stock solutions were diluted to make working solutions; in pure DMSO for irgarol, diuron, ZnPT and CuPT; in sterile ultra-pure water for $\mathrm{CuSO}_{4}$.

\subsection{Microalgal cultures}

The marine microalga Tisochrysis lutea ( $T$. lutea) CCAP 927/14 was purchased from the Culture Center of Algae and Protozoa (CCAP, Oban, Scotland). The marine diatom Skeletonema marinoi (S. marinoI) AC174, was purchased from the University of Caen Algobank (Caen, France). The marine microalgae Tetraselmis suecica (T. suecica) CCMP 904 was obtained from the Provasoli-Guillard 
National Center for Marine Algae and Microbiota (NCMA). Microalgal cultures were maintained in sterile f/2 (T. lutea and T. suecica) and f/2-Silica (S. marinoi) mediums (Guillard and Ryther, 1962; Guillard, 1975) at $20 \pm 1{ }^{\circ} \mathrm{C}$, in a thermostatic cham ber at $130 \mu \mathrm{mol} \mathrm{m}^{-2} \mathrm{~s}^{-1}$ (Quantometer Li-Cor Li-250 equipped with a spherical sensor), with a dark:light cycle of $8: 16 \mathrm{~h}$. Cultures were grown in $100 \mathrm{~mL}$ round borosilicate sterile glass flasks previously heated to $450^{\circ} \mathrm{C}$ for $6 \mathrm{~h}$ and autoclaved $20 \mathrm{~min}$ at $1211^{\circ} \mathrm{C}$ and then filled with $50 \mathrm{~mL}$ of sterile culture medium. Cultures were diluted weekly in order to maintain an exponential growth phase.

\subsection{Exposure experiments}

\subsubsection{Concentration-response experiments}

Concentration-response experiments were performed for each chemical/mixture to calculate the EC50, meaning the Effective Concentration inducing a 50\% inhibition on growth rate after a 96-h exposure. Toxicity assays were run in sterile 48-well transparent polystyrene microplates (Greiner BioOne $\mathrm{GmbH}$, cat. 677102 , untreated), each well being filled with $0.9 \mathrm{~mL}$ of sterile $\mathrm{f} / 2 \mathrm{or} \mathrm{f} / 2-\mathrm{Si}$ culture medium and $0.1 \mathrm{~mL}$ of microalgal culture. Microplates were covered with their own lid, allowing gas exchanges. Peripheral wells were not used in order to avoid edge effect (Caux et al., 1992; St-Laurent et al., 1992); instead, they were filled with sterile $0.2-\mu \mathrm{m}$ filtered ultra-pure water to prevent evaporation and maintain high humidity. One assay test was conducted per tested substance/mixture. Each assay consisted in the exposure to six concentrations (supplementary data: Figure S1, Table $\mathrm{S} 1$ ) in triplicates and six solvent-control (SC) containing the highest solvent percentage used in the microplate $(0.1 \%$ of DMSO). Specific growth rates for control with and without solvent are displayed in supplementary data (Table S2). Chemicals and solvent (for solvent-control condition) were spiked in separate sterile glass flasks (one glass flask per tested chemical and concentration) containing $25 \mathrm{~mL}$ of sterile culture medium prior to distribution in the triplicate wells of the microplate. After measurement of the cell density by flow cytometry (Accuri C6, Becton Dickinson Accuri ${ }^{\mathrm{TM}}$ ), $0.1 \mathrm{~mL}$ of the diluted microalgal culture was added in each assay well to reach a concentration of 20,000 cell $\mathrm{mL}^{-1}$ at the beginning of exposure. The final volume of each well was $1.0 \mathrm{~mL}$.

For binary mixture experiments, the approach of concentration-response surfaces was chosen (Gessner, 1995; White et al., 2004). This design provides data for the full range of possible combinations between two chemicals, which is data-demanding but remains the most elaborate and 
informative approach to evaluate the joint toxicity of two chemicals in binary mixture (Cedergreen et al., 2013). For being able to perform these experiments, the EC50 of the single chemicals, which are prerequisite, have been determined in preliminary experiments (Table 1; Figure 1). Concentrationresponse experiments were then carried out for single chemicals (considered as mixture ratios $100: 0 \%$ and $0: 100 \%$ ) and mixtures at three perceived effective concentration ratios of $75: 25 \%$, $50: 50 \%$ and $25: 75 \%$, using six concentrations in triplicates and six-solvent controls, as described above. As all possible combinations could not been investigated, six selected binary mixtures were tested using the previously mentioned design: diuron+irgarol; $\mathrm{ZnPT}+\mathrm{CuPT}$; diuron $+\mathrm{Cu}$; irgarol+Cu; diuron+ZnPT and $\mathrm{Cu}+\mathrm{ZnPT}$.

\subsubsection{Chemical stability assays}

The chemical stability of the biocides selected in this study was investigated in the microplate wells over time, during 24 or $96 \mathrm{~h}$ (Table 2 and supplementary data: Table S3). To that aim, an abiotic microplate assay was run for each chemical tested, under the same conditions as the concentrationresponse experiments (2.3.1). In order to specifically investigate the potential transchelation of $\mathrm{ZnPT}$ into CuPT, the microplate assays were run using a mixture of $\mathrm{ZnPT}$ and $\mathrm{Cu}$ at concentrations for which transchelation was suspected to happen. It is noteworthy that regarding the first results we obtained, transchelation was also assessed in biotic conditions using T. suecica. For each condition, 1- to $5-\mathrm{mL}$ of the spiked culture medium were taken off the wells into separate vials at the beginning of the assay, and after 6 and $96 \mathrm{~h}$ for diuron and irgarol, after 24 and $96 \mathrm{~h}$ for $\mathrm{ZnPT}$, CuPT and the mixture of $\mathrm{ZnPT}$ with $\mathrm{Cu}$ (with and without algae), and after $24 \mathrm{~h}$ for $\mathrm{Cu}$. The vials were then stored at $20^{\circ} \mathrm{C}$ before chemical analysis.

\subsection{Chemical analyses}

\subsubsection{Diuron and irgarol:}

Classical methods were used to quantify diuron and irgarol and the global protocol was adapted from Coquillé et al. (2018). Each abiotic sample (2.3.2) was diluted in ultra-pure water to reach a theoretical final concentration of $100 \mathrm{ng} \mathrm{L}^{-1}$ and $40 \mu \mathrm{L}$ of the diluted samples were directly analyzed by liquid chromatography (1290 Infinity system, Agilent Technologies, USA) coupled to tandem mass spectrometer (6460 triple quadrupole LC/MS system, Agilent Technologies, USA), after adding 
internal standards (diuron-d6, irgarol-d9). The separation was performed using a Kinetex C18 column and using a gradient of $5.00 \mathrm{mM}$ ammonium acetate with $0.1 \%$ acetic acid in ultra-pure water and pure methanol as mobile phases, with a flow rate of $0.50 \mathrm{~mL} \mathrm{~min}^{-1}$. Analyses were performed in multiple reaction monitoring mode (supplementary data: Table S4). The LOQ was $1.19 \mathrm{ng} \mathrm{L}^{-1}$ for diuron and $0.24 \mathrm{ng} \mathrm{L}^{-1}$ for irgarol.

\subsubsection{Copper:}

A classical method was adapted from Garbarino and Taylor (1996) to quantify Cu. Each abiotic sample (2.3.2) was diluted 50 times in ultra-pure water containing $0.2 \% \mathrm{HNO}_{3}$. Dissolved $\mathrm{Cu}$ concentrations in samples were determined on a X series II ICP-MS (Thermo Fisher Scientific®). An internal solution, containing In and Rh was added to the samples to correct signal drifts. The LOQ for Cu was $0.73 \mu \mathrm{g} \mathrm{L}^{-1}$. The accuracy and the precision of the method were evaluated using the NIST 2976 (National Institute of Standard and Technology) and SLRS-5 (National Research Council of Canada (CNRC)) certified reference materials. Measured concentrations of $\mathrm{Cu}$ agreed with recommended values to within $\pm 5 \%$.

\subsubsection{ZnPT and CuPT:}

Prior to extraction, the samples containing $\mathrm{ZnPT}$, CuPT or the mixture of $\mathrm{ZnPT}$ and $\mathrm{Cu}$ (with and without algae; 2.3.2) were centrifuged during 1 minute at $3000 \mathrm{~g}$. After half dilution with water containing the internal standard, $1000 \mu \mathrm{L}$ supernatant of the samples were directly injected and extracted using an on-line solid-phase extraction system Waters (Milford, Massachusetts, USA) XBridge ${ }^{\circledR}$ C8 Direct Connect cartridges with elution during the chromatography mobile phase. Separation was achieved by ultraperformance liquid chromatography (Acquity ${ }^{\circledR}$ HClass, Waters), using a Waters Acquity ${ }^{\circledR}$ UPLC BEH C18 column $(50 \times 2.1 \mathrm{~mm} ; 1.7 \mu \mathrm{m})$ and an elution gradient consisting of ammonium acetate $20.0 \mathrm{mM} /$ methanol. Detection relied on ultra-performance liquid chromatography and tandem mass spectrometry (MS-MS) (Xevo TQ-S, Waters).

Two curves of six-points calibration, one for ZnPT, one for CuPT were prepared extemporaneously in water and were treated like samples. Concentration range linearity was observed from $0.05 \mu \mathrm{g} \mathrm{L}^{-1}$ (LOQ) to $100 \mu \mathrm{g} \mathrm{L}^{-1}$ for CuPT and $0.05 \mu \mathrm{L} \mathrm{L}^{-1}$ (LOQ) to $50.0 \mu \mathrm{g} \mathrm{L}^{-1}$ for ZnPT. 


\subsection{Analysis of microalgal growth using microplate reader}

Microalgal growth was measured every $24 \mathrm{~h}$, during the light phase and at least two hours after its start, by the chlorophyll fluorescence. Microplates were analysed using a SAFIRE microplate reader (TECAN) with XFluor4beta Excel® macro as software. Excitation/emission wavelengths were: 450/684 $\mathrm{nm}$ (10 nm bandwidth), 9 reads were performed per well from the bottom, with an integration time of $20 \mu$ s. Each microplate was shaken during $20 \mathrm{~s}$ before the reading, using a Orbis Plus (Mikura Ltd) microplate shaker in orbital mode.

For each well, the growth rate was calculated, for each species and substance tested over the $96 \mathrm{~h}$ exposure period, with the following equation: $\mu=\ln \left(F_{t}-F_{0}\right) / t$, where $F_{t}$ was the fluorescence (a.u.) of the well at $t(h), \mu\left(h^{-1}\right)$ was the growth rate and $F_{0}$ the initial fluorescence intensity at $t=0 h$.

\subsection{Statistical analysis}

\subsubsection{Concentration-response}

Concentration-response analyses were carried out using R software 3.3.2 with 'drc' package (Ritz and Streibig, 2005; Ritz et al., 2015). For each chemical, tested using six concentrations in triplicates, a single three-parameters log-logistic regression model, Equation 1, was applied:

$$
U=\frac{d}{\left(1+\left(\frac{x}{\operatorname{EC} 50}\right)^{b}\right)}
$$

where $U$ is the response, in our case the $96 \mathrm{~h}$ growth rate $\left(\mu, \mathrm{h}^{-1}\right)$, at the concentration $x, d$ the upperlimit corresponding to the growth rates of the untreated algae and $b$ is the slope of the curve around EC50.

\subsubsection{Mixture analysis}

\subsubsection{Isobole model}

Isobolograms (Figure 2) permit the visualization of several isoboles, which consist of concentration combinations of two substances that yield the same effect. In this study, a $50 \%$ inhibition effect on growth rate was used. Predictions from the two reference isobole models, CA and IA, were calculated 
for each mixture based on the concentration response parameters of the single chemicals. To calculate the isobole for the CA model, Equation 2 was used:

$$
\sum_{i=1}^{n} \frac{z_{i}}{\mathrm{EC} x_{i}}=1
$$

where, $z_{i}$ is the concentration of the chemical $i$ in the mixture giving $\mathrm{x} \%$ effect and $\mathrm{EC} x_{i}$ is the effective concentration yielding the same effect as the mixture, in our case, EC50 for a $50 \%$ inhibition. The quotient $z_{i} / E C x_{i}$ corresponds to the dimensionless Toxic Units $\left(\operatorname{TU} x_{i}\right)$ that quantifies the relative contribution to toxicity of the individual chemical $i$ in the mixture of $n$ chemicals.

The response of a binary mixture of $X$ and $Y$ following the IA model predictions corresponds to the multiplication of the relative responses, where maximal growth rates are set to 1 and can be described as: $R_{\text {mix }}=R_{x} R_{y}$; the response of the chemical $Y$ in a mixture achieving a $50 \%$ inhibition effect is then: $R_{y}=0.5 / R_{x}$. Knowing the response of $Y$ at a given concentration of $X$ makes it possible to calculate the corresponding concentration of $Y$ by solving the equation of the chosen concentration-response model for $y$. Hence, solving Eq. 1 with $d=1$ for the concentration $z$, gives

$$
z=\operatorname{EC50}\left(\frac{1}{U}-1\right)^{1 / b}
$$

and $y$ can be determined using the EC50 and slope $(b)$ given by the concentration-response curve of chemical $Y$. The predicted concentrations of $X$ and $Y$ yielding a $50 \%$ inhibition effect can then be plotted on the isobologram.

The Hewlett and Vølund models (Hewlett, 1969; Vølund, 1992), that are extensions of the CA model were also tested. These two models are based on a four-parameters log-logistic model, with common upper and lower-limit; the latter being fixed to zero, thereby reducing it to a three-parameters model. Both models allow the isobole to describe either synergistic or antagonistic responses relative to CA. The Hewlett model uses the EC50 of the two chemicals $X$ and $Y$ and one additional parameter, giving symmetric deviations from CA, while the Vølund model introduces two additional parameters allowing for asymmetric deviations from the CA model (Ritz and Streibig, 2014). Further details about these models are available in (Cedergreen et al., 2007).

The Hewlett isobole model is described by: 


$$
\mathrm{EC} 50_{\text {mix }}=\left(\left(\frac{p_{X}}{\operatorname{EC} 50_{X}}\right)^{1 / \lambda}+\left(\frac{p_{Y}}{\operatorname{EC} 50_{Y}}\right)^{1 / \lambda}\right)^{-\lambda}
$$

where $p_{X}$ and $p_{Y}$ are the proportions of the chemicals $X$ and $Y$ in the mixture relative to the EC50 of the mixture, corresponding to multiplying Eq. 2 with $\mathrm{EC} 50_{\text {mix }}$ (making $p_{i}=z_{i} \mathrm{EC} 50_{\text {mix }}$ ) and $\lambda$ the interaction parameter that describes combination effects: if $\lambda=1$ the equation reduces to concentration addition; if $\lambda<1$ the isobole describes antagonism; if $\lambda>1$ it describes synergism.

The Vølund isobole model is described by:

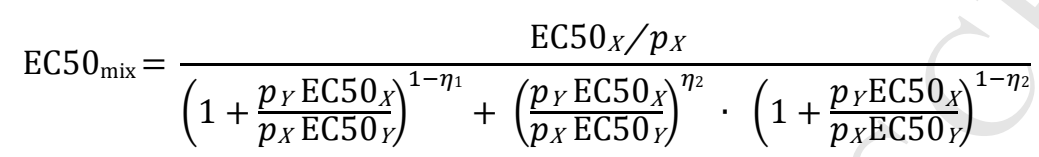

using two interaction parameters, $\eta_{1}$ and $\eta_{2}$ : if $\eta_{1}=\eta_{2}=1$ the model simplifies to the CA model; if $\eta_{1}$ and $\eta_{2}>1$ the isobole shows antagonism; if $\eta_{1}$ and $\eta_{2}<1$ it displays synergism. If $\eta_{1}>1 \eta_{2}<1$, or viceversa, the interaction is part synergistic and partly antagonistic.

The CA model (Eq. 2, two chemicals gives 5 parameters) was first tested against a simultaneous fit of all data to five concentration-response curves computed by the three-parameters log-logistic model using freely-varying slopes and EC50-values and a common upper-limit (11-parameters model). The two fits were compared using an $F$-test to test if the extended model describes the data significantly better than the reduced model: if $p>0.05$ there is no significant difference between the model predictions, hence, the reduced model (in this case CA) will be preferred. If the hypothesis of the previous test is rejected (i.e. the CA model do not describe the data well), extended models (Hewlett or Vølund) can be tested. To assess if an extended model provides a better fit to the data than the CA model, the extended model is tested against the simpler model (Hewlett vs. CA, and Vølund vs. Hewlett and CA) using the F-test.

\subsubsection{MIXTOX model}

The MIXTOX model provides an alternative approach to Hewlett and Vølund isobole models. The model is implemented in an Excel® macro and was developed by Jonker et al. (2005). The model also describes an entire concentration-response surface, not based on rays following a sigmoid curve, as described above, but rather models the entire surface mathematically including all data. This also 
means that data achieved using other designs than the ray design described above can be used, providing that the data cover the majority of the concentration-response surface. On the other hand, modelling the entire surface without the restrictions of each "ray" having to follow a sigmoid model, such as is implemented in the Hewlett and Vølund models, may have the consequence of the "rays" having other shapes than the sigmoid shape, which experience have shown most concentrationresponse relationships follow (Scholze, et al., 2001).

In the model developed by Jonker et al. (2005), the CA and IA models are implemented as described above, using knowledge of the upper-limit, slope and EC50 calculated by the three-parameters loglogistic model (Eq. 1) for the two single compounds. Deviations from the CA or IA models can be described by the addition of a single parameter, $a$, pulling the entire concentration-response surface below the plane of the reference model (synergism, $a<0$ ) or above the plane (antagonism, $a>0$ ). This model extension is called S/A (Synergism/Antagonism). Alternatively, an additional parameter can be added, $b$, allowing for asymmetric deviations from the reference model. In the MIXTOX concept, this model extension is called DR/DL (Dose Ratio/Dose Level-dependent deviation). The mathematical derivations of the models and interpretations are given in Jonker et al. (2005).

In order to fit the models to the experimental data, the built-in solver function (Excel®) is used to minimize the residual sum of squares (SS) by interacting with the parameters: upper-limit, slopes and EC50 as well as interaction parameters in the case of S/A and DR/DL model extensions. The lower the residual sum of squares is, the better is the fit of the experimental data to the model. A $X^{2}$ test is also performed to determine if S/A model extension provides a significantly better fit $(p<0.05)$ than the reference model (CA or IA), and similarly for $D R / D L$ vs. S/A and CA/IA.

\section{Results}

\subsection{Chemical analyses}

For each chemical, the nominal and measured concentrations of stock solutions (supplementary data: Table S3) were compared by calculating the percentages of variation, which were always below $10 \%$. The chemical concentrations in the microplate wells remained steady over time for diuron, irgarol or $\mathrm{Cu}$, although the measured concentration at the beginning of the exposure (t0) was slightly lower than targeted for diuron and irgarol (supplementary data: Table S3). The analysis of the samples containing 
only ZnPT or CuPT (Table 2) showed that more than half of the chemicals had disappeared after $24 \mathrm{~h}$ and that the concentrations were below $0.05 \mu \mathrm{g} \mathrm{L}^{-1}$ (LOQ) after $96 \mathrm{~h}$. Interestingly both $\mathrm{ZnPT}$ and CuPT were present at almost equimolar concentration at t0 and t24 in the samples supposed to contain only ZnPT. Note that $\mathrm{Cu}$ and $\mathrm{Zn}$, present at nominal concentrations of 2.50 and $5.00 \mu \mathrm{g} \mathrm{L}^{-1}$ (Table 2), are part of the $\mathrm{f} / 2$ medium as necessary micronutrients for algal growth. Similarly, for CuPT (Table 2), while the concentration at to was higher than expected, both ZnPT and CuPT were detected after $24 \mathrm{~h}$, even though no ZnPT was added nor detected at t0. As for ZnPT, no CuPT nor ZnPT were detected $(<\mathrm{LOQ})$ after $96 \mathrm{~h}$.

Samples containing the mixture of ZnPT with $\mathrm{Cu}$ without microalgae showed that $87.8 \mathrm{nM}$ of CuPT were present at t0, while only $47.9 \mathrm{nM}$ of $\mathrm{ZnPT}$ were added to the culture medium (Table 2). In the same sample, $30.3 \mathrm{nM}$ of ZnPT were also detected, giving a sum of PT-associated metals about twice the concentration added. This was unexpected, but it was confirmed by the analytical method that PT contamination was not occurring in the inserted blank samples. After $24 \mathrm{~h}$, the concentration of CuPT almost decreased by half, while the concentration of ZnPT slightly increased. After $96 \mathrm{~h}$, neither ZnPT nor CuPT were detected (<LOQ). Samples containing the same mixture with $T$. suecica showed very similar results (Table 2), the only difference being a greater decrease after $24 \mathrm{~h}$ in both ZnPT and CuPT concentrations.

\subsection{Toxicity of single chemicals among microalgal species}

For all species tested, the maximum DMSO concentration used in the experiments $(0.1 \%)$ did not induce any significant differences on growth rate compared to control (supplementary data: Table S2). The EC50 values obtained for the three algal species ranged from 0.34 to $0.85 \mu \mathrm{g} \mathrm{L}^{-1}$ for irgarol, 3.73 to $10.3 \mu \mathrm{g} \mathrm{L}^{-1}$ for diuron, 1.60 to $18.0 \mu \mathrm{g} \mathrm{L}^{-1}$ for CuPT, 1.30 to $256 \mu \mathrm{g} \mathrm{L}^{-1}$ for ZnPT and 703 to $1449 \mu \mathrm{g} \mathrm{L}^{-1}$ for Cu (Figure 1, Table 1). T. lutea was the most sensitive species for all tested chemicals except CuPT, which exhibited a slightly higher toxicity towards $S$. marinoi. The diatom was the less sensitive to the two PSII inhibitors, whereas T. suecica was the less sensitive to $\mathrm{Cu}$ and the organometals ZnPT and CuPT. EC50 of ZnPT and CuPT were similar and between 1 and $2 \mu \mathrm{g} \mathrm{L}^{-1}$ for T. Iutea and S. marinoi while much higher values of $256 \pm 18.1 \mu \mathrm{g} \mathrm{L}^{-1}$ and $18.0 \pm 1.50$ were obtained for $T$. suecica. Based on the EC50, the toxicity of the five tested chemicals can be ranked as follows 
for the three species, from the most toxic to the least toxic: irgarol $>$ CuPT $>$ ZnPT $>$ diuron $>$ Cu for $T$. lutea and S. marinoi; irgarol > diuron > CuPT > ZnPT > Cu for T. suecica.

\subsection{Toxicity of binary mixtures}

\subsubsection{Similar mode of action}

The mixture toxicity of diuron and irgarol on T. lutea (Figure 3) was found to be additive, as evidenced by the EC50 of the $50: 50 \%$ mixture $\left(\Sigma \mathrm{TU}_{50: 50}\right)$ of $1.01 \pm 0.08$ (Table 3$)$. A slight but significant synergism was observed for S. marinoi and T. suecica (Figure 3), with $\Sigma T U_{50: 50}$ of $0.92 \pm 0.04$ and $0.79 \pm 0.05$, respectively (Table 3$)$ and a better fit of the Hewlett model tested against the CA model $(p$ $=0.03 ; p<10^{-3}$ ) was obtained, describing slight synergism for $S$. marinoi and $T$. suecica, respectively. The mixture toxicity of the two organometals $\mathrm{ZnPT}$ and CuPT was additive for T. lutea, antagonistic for S. marinoi and synergistic for $T$. suecica (Figure 3) with $\Sigma \mathrm{TU}_{50: 50}$ of $0.94 \pm 0.05,1.15 \pm 0.03$ and $0.81 \pm$ 0.57 TU (Table 3), respectively. The Hewlett model described the data significantly better than the CA model for $S$. marinoi and T. suecica $\left(p<10^{-3} ; p=0.04\right)$. It can be noted that for every case where an extended model provided a better fit than the CA predictions, the Hewlett model was preferred to the Vølund model, thus meaning that the deviations were symmetric compared to the CA isobole.

Using the MIXTOX model, interactive effects were the same as with the isobole model: two mixtures were additive, three were synergistic and one was antagonistic, compared to the CA model predictions. If looking at the best reference model for mixtures of chemicals sharing the same MoA, the CA model always provided a better fit than the IA model. Results for the MIXTOX model are summarized in Table 3.

\subsubsection{Dissimilar mode of action}

Mixtures of diuron or irgarol together with $\mathrm{Cu}$ on $T$. lutea and $T$. suecica led to very similar findings (Figure 4, Table 3). For T. lutea, $\Sigma \mathrm{TU}_{50: 50}$ were $1.95 \pm 0.05$ and $1.95 \pm 0.08$; for $T$. suecica the $\Sigma \mathrm{TU}_{50: 50}$ were $1.47 \pm 0.14 \mathrm{TU}$ and $1.53 \pm 0.07$, for diuron:Cu and irgarol:Cu mixtures, respectively. The twoparameter Vølund model was found to better fit the data than the CA and Hewlett models $\left(p<10^{-3}\right)$ for both mixtures with $T$. lutea and for the mixture of diuron and $\mathrm{Cu}$ for $T$. suecica. The interaction effect was asymmetric and antagonistic compared to the CA model predictions: the magnitude of the 
antagonism was stronger when 50 or $75 \%$ of the effect was due to $\mathrm{Cu}$. Regarding the mixture of irgarol and $\mathrm{Cu}$ for $T$. suecica, the Hewlett model was the best fitting model $\left(p<10^{-3}\right)$ describing antagonism compared to the CA model. For S. marinoi, the $\Sigma \mathrm{TU}_{50: 50}$ of the diuron:Cu mixture was 1.15 \pm 0.04 . The Hewlett model provided the best fit $\left(p<10^{-3}\right)$, however the antagonism was not as strong as for the two other species (Figure 4, Table 3). Again, the antagonism was particularly noticeable when 50 or $75 \%$ of the mixture effect was due to $\mathrm{Cu}$. The mixture of irgarol and $\mathrm{Cu}$ was additive, with a $\Sigma \mathrm{TU}_{50: 50}$ of $1.03 \pm 0.05$, for the diatom S. marinoi.

For the mixture of diuron and $\mathrm{ZnPT}$ on $T$. lutea and T. suecica (Figure 4), the $\Sigma T U_{50: 50}$ were $1.25 \pm$ 0.09 and $1.08 \pm 0.08$ (Table 3 ) and the Hewlett model provided the best fit $\left(p<10^{-3}\right)$, describing slight antagonism in both cases. For $S$. marinoi, the $\Sigma \mathrm{TU}_{50: 50}$ was $0.98 \pm 0.02$, the $\mathrm{CA}$ model provided the best fit to the data, indicating additivity.

The $\Sigma \mathrm{TU}_{50: 50}$ was $2.20 \pm 0.03$ for the mixture of $\mathrm{Cu}$ and $\mathrm{ZnPT}$ on $T$. lutea (Table 3), meaning a very strong antagonism for this mixture ratio, which was lower for the two other mixture ratios (Figure 4). The Hewlett model provided the best fit $\left(p<10^{-3}\right)$. The same response pattern was observed for the diatom S. marinoi, the $\Sigma \mathrm{TU}_{50: 50}$ was $2.43 \pm 0.25$, also implying a very strong antagonism for this mixture ratio. Similarly, the Hewlett model provided a better fit than the CA model $\left(p<10^{-3}\right)$. Finally, for T. suecica, the response pattern was opposite compared to the two other species (Figure 4), as evidenced by the $\Sigma T U_{50: 50}$ of $0.16 \pm 0.004$ (Table 3). The Hewlett model provided the best fit $\left(p<10^{-3}\right)$, describing a very strong synergism.

Using the MIXTOX model (Table 3), the results were identical to what was found with the isobole model: two mixtures were additive, 9 were antagonistic and one was synergistic, compared to the CA model predictions. Seven mixtures out of 12 were better predicted by the IA model than the CA model (Table 3). Interestingly, in three cases (mixtures of diuron:ZnPT on T. lutea and Cu:ZnPT on T. lutea and S. marinoI) the interactive effect switches from antagonism to synergism when considering the IA model as reference instead of the CA model. Results for the MIXTOX model are summarized in Table 3. 


\section{Discussion}

\subsection{Toxicity of the single chemicals}

Regarding the toxicity of single chemicals towards the three species of microalgae, it appears that the three species exhibited roughly the same sensitivity towards the tested compounds (Figure 1, Table 1), except for ZnPT and CuPT to which T. suecica was less sensitive. Such values are in agreement with previously reported EC50 values for these compounds (Koutsaftis and Aoyama, 2006; Yamada, 2006; Buma et al., 2009; Onduka et al., 2010; Bao et al., 2011; Avelelas et al., 2017).

Even though they share the same MoA, irgarol was approximately 10 -fold more toxic than diuron for the three algal species, likely due to its higher affinity for the $Q_{B}$ niche (Chesworth et al., 2004) that might be explained by its higher Log $K_{\text {ow }}$.

T. suecica was less sensitive to the organometals: ZnPT was 200 -fold and 130 -fold more toxic to T. lutea and S. marinoi than to T. suecica, respectively; CuPT was 15-fold more toxic to T. lutea and S. marinoi than to $T$. suecica. The chlorophyte also exhibited a different sensitivity to ZnPT and CuPT as CuPT was 14-fold more toxic than ZnPT. It was not the case for T. lutea and S. marinoi, for which ZnPT and CuPT toxicity was similar (less than 2-fold difference). Since only very few studies reported on the toxicity and MoA of ZnPT and CuPT towards microalgae, these differences in sensitivity are, at the present time, difficult to interpret.

Results of the chemical analyses showed that the presence of $\mathrm{Cu}$ as micronutrient in the culture medium induced an almost immediate transchelation of about half of the ZnPT into CuPT (Table 2), hence indicating that the toxicity of $\mathrm{ZnPT}$ might have been modified by the presence of newly generated CuPT in the medium. Surprisingly, after $24 \mathrm{~h}$, some CuPT also transchelated into ZnPT in the presence of $\mathrm{Zn}$ ions, which were also added as part of the $f / 2$ medium. This was not expected since CuPT is thought to be a more stable PT-metal complex than ZnPT (Grunnet and Dahllöf, 2005). In addition to the interaction between $\mathrm{Cu}$ and $\mathrm{ZnPT}$, EDTA, which is part of the $\mathrm{f} / 2$ culture medium in the form of $\mathrm{Na}_{2} \mathrm{EDTA}$, was also shown to interact with $\mathrm{ZnPT}$, by chelating zinc from ZnPT, thus dissociating ZnPT into NaPT (Kim et al., 2017). As NaPT form was not measured in the chemical analyses performed, there is no evidence indicating the formation of this substance in our experiments. Nevertheless, as ZnPT is able to interact with both $\mathrm{Cu}$ and EDTA, one should be very careful when testing ZnPT together with these substances. Chemical analyses should be performed 
and avoiding the presence of $\mathrm{Cu}$ and EDTA in the culture medium would probably be required to ensure that the observed toxicity is not due to CuPT or NaPT instead of ZnPT.

Concerning $\mathrm{Cu}$ toxicity, the EC50 values obtained in this study were within the same range than already reported for the marine microalgae $C$. gracilis and T. pseudonana (Koutsaftis and Aoyama, 2006; Bao et al., 2008), while 30- to 140-fold smaller EC50 values were reported for Tetraslemis sp. and Isochrysis sp. These discrepancies might be due to the presence of EDTA, whose effect on trace metal toxicity is still controversial. Indeed, a recent study conducted by Expósito et al. (2017) showed that the percentage of $\mathrm{Cu}^{2+}$ ions in test tubes containing $2.50 \mu \mathrm{g} \mathrm{L}^{-1}$ of $\mathrm{Cu}$ (which is the concentration of $\mathrm{Cu}$ in the $\mathrm{f} / 2$ medium) in ASTM medium ( $6.9 \mu \mathrm{M} \mathrm{Na}{ }_{2}$ EDTA) represented only $0.02 \%$ of the total $\mathrm{Cu}$ concentration, the rest of the Cu being complexed with EDTA. Moreover, Tubbing et al. (1994) demonstrated that $\mathrm{Cu}$ is biologically available to the microalgae $S$. capricornutum when complexed with EDTA while Ma et al. (2003) observed increasing EC50 values with increasing EDTA concentrations when exposing the microalgae Scenedesmus subspicatus to $\mathrm{Cu}$. As a result, the presence of EDTA in the growth medium might have lowered the toxicity of $\mathrm{Cu}$ in our tests.

\subsection{Mixtures of chemicals with similar modes of action}

The principle behind the CA model is that non-interacting chemicals only differ in potency, so if they share the same molecular target, they can be viewed as dilutions of the same chemical, which will always conform to the CA model (Berenbaum, 1989). For that reason, it is generally thought that the CA model is best at predicting mixture toxicity of chemicals that share the same MoA. This was confirmed in this study as the CA model gave better predictions than the IA model for all mixtures of chemicals sharing the same MoA (Table 3).

The mixture of the two PSII inhibitors diuron and irgarol (Figure 3) was found to be additive for T. lutea (Table 3), while it appeared to be slightly synergistic on S. marinoi and T. suecica. Synergism in diuron:irgarol mixtures has already been reported on the seagrass Zostera marina (Chesworth et al., 2004) and microalgae S. capricornutum, C. gracilis and T. suecica (Fernandez-Alba et al., 2002; Koutsaftis and Aoyama, 2006). It has often been argued that, although these two compounds share the same MoA, they come from two different chemical families: phenylureas for diuron and $S$-triazines for irgarol. Hence, it cannot be excluded that they can have dissimilar toxicokinetic-toxicodynamic (i.e. the processes responsible for toxicity over time at the level of organisms) (Gramatica et al., 2001; 
Borgert et al., 2004), as well as different secondary targets that could be responsible for the synergism observed in some cases.

Mixture of ZnPT and CuPT (Figure 3) was additive on T. lutea and very close to additivity for $S$. marinoi and T. suecica (Table 3). The MoA of these two compounds on microalgae is not well known, however, the additivity resulting from their mixture seems to point out a common MoA.

Regarding mixtures that exhibited a significant deviation from the CA model predictions, one can argue that the deviations are too small to be considered as biologically significant. Indeed, as stated in Belden et al. (2007), a factor of two between expected and observed values should be respected to define biologically significant and repeatable interactions. Moreover, small deviations are very often difficult to reproduce (Cedergreen et al., 2007), although it also depends on the test organism. With respect to these statements, previously mentioned deviations from the CA model cannot be regarded as biologically significant.

\subsection{Mixtures of chemicals with dissimilar modes of action}

Like the CA model, the IA model is based on the assumption of non-interacting chemicals. It differs, however, as it is based on binomial endpoints and populations of independent organisms (Greco et al., 1995). Even though such assumptions are not fulfilled when considering the growth rate in a microalgal culture as the endpoint, the IA model has been found to provide good predictions of mixtures of chemicals with dissimilar modes of action (Backhaus et al., 2004). Cedergreen et al. (2008) explored the accuracy of both the CA and IA models on 98 mixtures of pesticides and pharmaceuticals on different organisms, and found that neither CA nor IA gave better predictions than the other. Thus, the predictability of both models was tested in this study.

In a study from Koutsaftis and Aoyama (2006), mixtures of diuron or irgarol together with $\mathrm{Cu}$ on the diatom Chaetoceros gracilis were found to be synergistic compared to the CA model, the synergism being stronger for the diuron and $\mathrm{Cu}$ mixture. It was the opposite in this study, as the mixtures were antagonistic for the three species, especially $T$. lutea and $T$. suecica (Figure 4, Table 3). Very similar responses were obtained with the diuron: $\mathrm{Cu}$ and irgarol:Cu mixtures and interestingly, the magnitude of the antagonism observed for these mixtures depends on the species: strong for $T$. lutea, moderate for $T$. suecica and close to additivity for $S$. marinoi. These differences might indicate that the observed antagonism is not due to a chemical interaction between diuron and Cu happening outside the cell, as 
if it had been the case, the same pattern would have been expected for the three species. Therefore, the antagonism might rather be due to a specific interaction with the photosynthetic apparatus, since it is the target of both diuron/irgarol and Cu. Teisseire et al. (1999) found a slight antagonistic effect for the mixture of diuron together with $\mathrm{Cu}$ on the growth of Lemna minor and made the hypothesis that diuron might have a protective effect against $\mathrm{Cu}$ by stimulating the activity of antioxidant enzymes like ascorbate peroxidase or glutathione reductase and/or increasing the numbers of photosystems and thus reducing the number of photosystems damaged by $\mathrm{Cu}$.

Mixture of $\mathrm{Cu}$ together with ZnPT was previously studied several times (Mochida et al., 2006; Zhou et al., 2006; Bao et al., 2008) to explore the potential transchelation of ZnPT into CuPT which could lead to unpredictable results and sometimes remarkable synergy. In our case, this mixture led to very contrasted results: strong antagonism for $T$. lutea and S. marinoi and strong synergism for $T$. suecica (Figure 4, Table 3). No synergism was expected for this mixture on T. lutea and S. marinoi because they both exhibit a similar sensitivity to the two organometals. However, the strong antagonism observed for the $50: 50 \%$ mixture ratio was not expected either and remains to be explained. Performing additional chemical analyses might permit to understand the phenomenon lying behind the antagonism observed. For the chlorophyte T. suecica, as CuPT was 14-fold more toxic than ZnPT (Table 1), strong synergism was expected for this mixture, assuming that higher amount of CuPT would be produced when increasing the concentration of $\mathrm{Cu}$ mixed with ZnPT. The response obtained was clearly synergistic and was consistent with the chemical analyses which demonstrated the presence of CuPT when ZnPT was mixed with $\mathrm{Cu}$ (Table 2). The observed transchelation even yielded more CuPT at to than could be accounted for by the PT added as ZnPT. This discrepancy could possibly be explained by the presence of non-complexed pyrithione $(\mathrm{Hydroxy}-2(1 \mathrm{H})$ pyridinethione) molecules in the $\mathrm{ZnPT}$ stock and working solutions. The magnitude of the synergism varied among the three mixture ratios, which seems to indicate that the amount of CuPT formed might also depend on the concentrations of both $\mathrm{ZnPT}$ and $\mathrm{Cu}$ in the culture medium. Indeed, the more $\mathrm{ZnPT}$ (and so the less $\mathrm{Cu}$ ) there is in the mixture, the more toxic the mixture gets (Figure 4), as demonstrated by the $\Sigma T U$ of the different mixture rays which were $0.54 \pm 0.04,0.16 \pm 0.004$ and 0.08 \pm 0.003 for the $75: 25 \%, 50: 50 \%$ and $25: 75 \%(\mathrm{Cu}: \mathrm{ZnPT})$ mixtures, respectively.

Contrary to what was found for mixtures of chemical sharing the same MoA, the IA model was equal, if not better than the CA model, for predicting the toxicity of mixture with dissimilar MoA. However, as 
already stated in previous studies (Junghans et al., 2006; Kortenkamp et al., 2009), the CA model should be preferred in terms of regulation as it provides more conservative predictions than the IA model. Nearly half of the mixtures of chemicals having dissimilar MoA induced deviations of at least a factor of two from the CA model predictions and could thus be considered as biologically significant, according to Belden et al. (2007).

The two modelling approaches (isobole versus MIXTOX) each have their strengths and weaknesses. The isobole model is easily usable with the 'drc' package in $\mathrm{R}$ opensource software and provides visual representations of interactions with isobolograms but requires a specific data format and currently only has CA implemented. The MIXTOX implementation in Excelß has a more user-friendly interface, is more flexible in terms of input data and has both CA and IA implemented. However, it does not provide fitted dose-response parameter, nor a good visual presentation of data. Mathematically deviations from the reference models are described differently in the two approaches, but when applied to data, the results in terms of type and degree of deviation is similar, as also demonstrated in Cedergreen et al. (2007). Thus, one should choose either of the two according to the chosen experimental design and goals of the study.

\section{Conclusion and outlook}

Evaluating the toxicity of antifouling binary mixtures towards three species of marine microalgae revealed several points of interest:

- Both the sensitivity to single chemicals and the interactive effects resulting from mixtures were different among the three microalgal species.

- The two modelling approaches used for predicting the mixture toxicity provided similar results.

- The Concentration Addition (CA) model should be preferred compared to the Independent Action (IA) model, as it provides more conservative predictions, is easier to use and implemented in the opensource software R ('drc' package).

- Even though significant, slight deviations from the reference models should be interpreted very cautiously regarding their "biological" significance.

- The chemical analyses performed pointed out the very low stability of ZnPT and its ability to rapidly transchelate into CuPT in the presence of $\mathrm{Cu}^{2+}$ ions. 
- $\quad$ The demonstrated transchelation of ZnPT into CuPT was responsible for the strong synergy observed in the mixture of $\mathrm{ZnPT}$ and $\mathrm{Cu}$ towards T. suecica.

The results underline the importance of studying mixtures of antifouling chemicals co-occurring in locations close to harbors, careening areas and marinas. As the complex chemistry of organometals together with copper induced severe synergy for one species, it would be interesting to closer investigate the environmental concentrations of these chemicals in contaminated sites together with their resulting toxicity to the local aquatic community.

\section{Acknowledgements}

This study has been carried out with financial support from the French National Research Agency (ANR) in the frame of the Investments for the future program, within the Cluster of Excellence COTE (ANR-10-LABX-45). We also want to thank Anja Weibell for her technical assistance, Helle Marcussen, Nikoline Juul Nielsen, Joël Knoery and Emmanuelle Rozuel for the copper analyses and Nathalie Tapie for the diuron and irgarol analyses. We also thank two anonymous reviewers for their comments, which helped us to improve the quality of this manuscript.

\section{References}

Avelelas, F., Martins, R., Oliveira, T., Maia, F., Malheiro, E., Soares, A.M.V.M., Loureiro, S., Tedim, J., 2017. Efficacy and Ecotoxicity of Novel Anti-Fouling Nanomaterials in Target and Non-Target Marine Species. Mar. Biotechnol. 19, 164-174. doi:10.1007/s10126-017-9740-1

Backhaus, T., Arrhenius, Å., Blanck, H., 2004. Toxicity of a mixture of dissimilarly acting substances to natural algal communities: Predictive power and limitations of independent action and concentration addition. Environ. Sci. Technol. 38, 6363-6370. doi:10.1021/es0497678

Bao, V.W.W., Leung, K.M.Y., Kwok, K.W.H., Zhang, A.Q., Lui, G.C.S., 2008. Synergistic toxic effects of zinc pyrithione and copper to three marine species: Implications on setting appropriate water quality criteria. Mar. Pollut. Bull. 57, 616-623. doi:10.1016/j.marpolbul.2008.03.041

Bao, V.W.W., Leung, K.M.Y., Qiu, J.W., Lam, M.H.W., 2011. Acute toxicities of five commonly used antifouling booster biocides to selected subtropical and cosmopolitan marine species. Mar. Pollut. Bull. 62, 1147-1151. doi:10.1016/j.marpolbul.2011.02.041 
Baron, M., Arellano, J.B., Gorge, J.L., 1995. Copper and photosystem II: a controversial relationship. Physiol. Plant. 94, 174-180.

Beardall, J., Raven, J.A., 2016. Carbon acquisition by microalgae, in: Borowitzka, M.A., Beardall, J., Raven, J.A. (Eds.), The Physiology of Microalgae. Springer International Publishing, pp. 89-99. doi:10.1007/978-3-319-24945-2_4

Belden, J.B., Gilliom, R.J., Lydy, M.J., 2007. How well can we predict the toxicity of pesticide mixtures to aquatic life? Integr. Environ. Assess. Manag. 3, 364-372. doi:10.1002/ieam.5630030307

Berenbaum, M.C., 1989. What is synergy? Pharmacol. Rev. 41, 93 LP-141.

Borgert, C.J., Quill, T.F., McCarty, L.S., Mason, A.M., 2004. Can mode of action predict mixture toxicity for risk assessment? Toxicol. Appl. Pharmacol. 201, 85-96. doi:10.1016/j.taap.2004.05.005

Buma, A.G.J.J., Sjollema, S.B., van de Poll, W.H., Klamer, H.J.C., Bakker, J.F., 2009. Impact of the antifouling agent Irgarol 1051 on marine phytoplankton species. J. Sea Res. 61, 133-139. doi:10.1016/j.seares.2008.11.007

Caquet, T., Roucaute, M., Mazzella, N., Delmas, F., Madigou, C., Farcy, E., Burgeot, T., Allenou, J.P.P., Gabellec, R., 2013. Risk assessment of herbicides and booster biocides along estuarine continuums in the Bay of Vilaine area (Brittany, France). Environ. Sci. Pollut. Res. 20, 651-666. doi:10.1007/s11356-012-1171-y

Caux, P.-Y., Blaise, C., Leblanc, P., Tache, M., 1992. A phytoassay procedure using fluorescence induction. Environ. Toxicol. Chem. 11, 549-557. doi:10.1002/etc.5620110413

different molecular target sites. Environ. Toxicol. Chem. 27, 1621-1632. doi:10.1897/07-474.1

Cedergreen, N., Kamper, A., Streibig, J.C., 2006. Is prochloraz a potent synergist across aquatic species? A study on bacteria, daphnia, algae and higher plants. Aquat. Toxicol. 78, 243-252. doi:10.1016/j.aquatox.2006.03.007

Cedergreen, N., Kudsk, P., Mathiassen, S.K., Sørensen, H., Streibig, J.C., 2007. Reproducibility of Binary-Mixture Toxicity Studies. Environ. Toxicol. Chem. 26, 149. doi:10.1897/06-196R.1

Cedergreen, N., Christensen, A.M., Kamper, A., Kudsk, P., Mathiassen, S.K., Streibig, J.C., Sørensen, H., 2008. A review of independent action compared to concentration addition as reference models for mixtures of compounds with

Cedergreen, N., Svendsen, C., Backhaus, T., 2013. Toxicity Prediction of Chemical Mixtures, in: 
Encyclopedia of Environmental Management. Taylor \& Francis, New York. doi:10.1081/E-EEM120046684

Cedergreen, N., 2014. Quantifying synergy: A systematic review of mixture toxicity studies within environmental toxicology. PLoS One 9, e96580. doi:10.1371/journal.pone.0096580

Chandler, C.J., Segel, I.H., 1978. Mechanism of the Antimicrobial Action of Pyrithione: Effects on Levels, and Protein Synthesis Mechanism of the Antimicrobial Action of Pyrithione: Effects on Membrane Transport, ATP Levels, and Protein Synthesis. Antimicrob. Agents Chemother. 14, 60-68. doi:10.1128/AAC.14.1.60.Updated

Chesworth, J.C., Donkin, M.E., Brown, M.T., 2004. The interactive effects of the antifouling herbicides Irgarol 1051 and Diuron on the seagrass Zostera marina (L.). Aquat. Toxicol. 66, 293-305. doi:10.1016/j.aquatox.2003.10.002

Coquillé, N., Ménard, D., Rouxel, J., Dupraz, V., Éon, M., Pardon, P., Budzinski, H., Morin, S., Parlanti, É., Stachowski-Haberkorn, S., 2018. The influence of natural dissolved organic matter on herbicide toxicity to marine microalgae is species-dependent. Aquat. Toxicol. 198, 103-117. doi:10.1016/j.aquatox.2018.02.019

Cozic, V., Durand, G., 2013. Mission d'étude pour réduire les impacts du carénage sur le milieu marin. Rapport phase 2 : Evaluer les équipements existants (cales et aires de carénage avec systèmes de traitement). IDHESA Bretagne Océane.

Devilla, R.A., Brown, M.T., Donkin, M., Tarran, G.A., Aiken, J., Readman, J.W., 2005. Impact of antifouling booster biocides on single microalgal species and on a natural marine phytoplankton community. Mar. Ecol. Prog. Ser. 286, 1-12. doi:10.3354/meps286001

Dinning, A.J., Al-Adham, I.S.I., Austin, P., Charlton, M., Collier, P.J., 1998a. Pyrithione biocide interactions with bacterial phospholipid head groups. J. Appl. Microbiol. 85, 132-140. doi:10.1046/j.1365-2672.1998.00477.x

Dinning, A.J., Al-Adham, I.S.I., Eastwood, I.M., Austin, P., Collier, P.J., 1998b. Pyrithione biocides as inhibitors of bacterial ATP synthesis. J. Appl. Microbiol. 85, 141-146. doi:10.1046/j.13652672.1998.00478.x

Doose, C.A., Ranke, J., Stock, F., Bottin-Weber, U., Jastorff, B., Gjersten, B., Doeskeland, S., Jastorff, B., Lanotte, M., 2004. Structure-activity relationships of pyrithiones - IPC-81 toxicity tests with the antifouling biocide zinc pyrithione and structural analogs. Green Chem. 6, 259-266. 
doi:10.1039/B314753C

El Berdey, A., Juneau, P., Pirastru, L., Popovic, R., 2000. Application of the PAM fluorometric method for determination of copper toxicity to microalgae and duckweed, in: Persoone, G., Janssen, C., De Coen, W. (Eds.), New Microbiotests for Routine Toxicity Screening and Biomonitoring. Springer US, Boston, MA, pp. 135-140. doi:10.1007/978-1-4615-4289-6_11

Environment Agency, 1998. Environmental problems from antifouling agents: survey of manufacturers, chandlers (suppliers) and treatment sites. Technical Report P215.

Expósito, N., Kumar, V., Sierra, J., Schuhmacher, M., Giménez Papiol, G., 2017. Performance of Raphidocelis subcapitata exposed to heavy metal mixtures. Sci. Total Environ. 601-602, 865873. doi:10.1016/j.scitotenv.2017.05.177

Fernandez-Alba, A.R.R., Piedra, L., Mezcua, M., Hernando, M.D.D., 2002. Toxicity of Single and Mixed Contaminants in Seawater Measured with Acute Toxicity Bioassays. Sci. World J. 2, 1115-1120. doi:10.1100/tsw.2002.221

Franklin, N.M., Stauber, J.L., Lim, R.P., Petocz, P., 2002. Toxicity of metal mixtures to a tropical freshwater alga ( Chlorella sp.): The effect of interactions between copper, cadmium, and zinc on metal cell binding and uptake. Environ. Toxicol. Chem. 21, 2412-2422. doi:10.1002/etc.5620211121

Garbarino, J.R., Taylor, H.E., 1996. Inductively coupled plasma-mass spectrometric method for the determination of dissolved trace elements in natural water. Open-File Report 94-358., U.S. Geological Survey.

Gessner, P.K., 1995. Isobolographic analysis of interactions: an update on applications and utility. Toxicology 105, 161-179. doi:10.1016/0300-483X(95)03210-7

Gramatica, P., Vighi, M., Consolaro, F., Todeschini, R., Finizio, a., Faust, M., 2001. QSAR approach for the selection of congeneric compounds with a similar toxicological mode of action. Chemosphere 42, 873-883. doi:10.1016/S0045-6535(00)00180-6

Greco, W.R., Bravo, G., Parsons, J.C., 1995. The search for synergy: a critical review from a response surface perspective. Pharmacol. Rev. 47.

Grunnet, K.S., Dahllöf, I., 2005. Environmental fate of the antifouling compound zinc pyrithione in seawater. Environ. Toxicol. Chem. 24, 3001. doi:10.1897/04-627R.1

Guillard, R.R.L., Ryther, J.H., 1962. Studies of marine planktonic diatoms. I. Cyclotella nana Hustedt 
and Detonula confervacea (Cleve) Gran. Can. J. Microbiol. 8, 229-239. doi:10.1139/m62-029

Guillard, R.R.L., 1975. Culture of Phytoplankton for Feeding Marine Invertebrates, in: Smith, W.L., Chanley, M.H. (Eds.), Culture of Marine Invertebrate Animals SE - 3. Springer US, Boston, MA, pp. 29-60. doi:10.1007/978-1-4615-8714-9_3

Hasan, C.K., Turner, A., Readman, J., Frickers, T., 2014. Environmental Risks Associated with Booster Biocides Leaching from Spent Anti-Fouling Paint Particles in Coastal Environments. Water Environ. Res. 86, 2330-2337. doi:10.2175/106143014X14062131178835

Hewlett, P.S., 1969. Measurement of the potencies of drug mixtures. Biometrics 25, 477-487. doi: $10.2307 / 2528900$

Jonathan, M.P., Roy, P.D., Thangadurai, N., Srinivasalu, S., Rodríguez-Espinosa, P.F., Sarkar, S.K., Lakshumanan, C., Navarrete-López, M., Muñoz-Sevilla, N.P., 2011. Metal concentrations in water and sediments from tourist beaches of Acapulco, Mexico. Mar. Pollut. Bull. 62, 845-850. doi:10.1016/j.marpolbul.2011.02.042

Jones, R.J., Kerswell, A.P., 2003. Phytotoxicity of Photosystem II (PSII) herbicides to coral. Mar. Ecol. Prog. Ser. 261, 149-159. doi:10.3354/meps261149

Jonker, M.J., Svendsen, C., Bedaux, J.J.M., Bongers, M., Kammenga, J.E., 2005. Significance testing of synergistic/antagonistic, dose level-dependent, or dose ratio-dependent effects in mixture dose-response analysis. Environ. Toxicol. Chem. 24, 2701-2713.

Junghans, M., Backhaus, T., Faust, M., Scholze, M., Grimme, L., 2006. Application and validation of approaches for the predictive hazard assessment of realistic pesticide mixtures. Aquat. Toxicol. 76, 93-110. doi:10.1016/j.aquatox.2005.10.001

Kim, T.H., Jung, G.H., Lee, E.H., Park, H.R., Lee, J.K., Kim, H.G., 2017. Development and validation of liquid chromatography-tandem mass Spectrometry method for simultaneous determination of zinc pyrithione and pyrithione in shampoos. Acta Chromatogr. 1-6. doi:10.1556/1326.2017.00294

Konstantinou, I.K., Albanis, T.A., 2004. Worldwide occurrence and effects of antifouling paint booster biocides in the aquatic environment: a review. Environ. Int. 30, 235-248. doi:10.1016/S01604120(03)00176-4

Kortenkamp, A., Backhaus, T., Faust, M., 2009. State of the Art Report on Mixture Toxicity - Final Report.

Report 1-391. 
doi:http://ec.europa.eu/environment/chemicals/pdf/report_Mixture\%20toxicity.pdf

Koutsaftis, A., Aoyama, I., 2006. The interactive effects of binary mixtures of three antifouling biocides and three heavy metals against the marine algae Chaetoceros gracilis. Environ. Toxicol. 21, 432-439. doi:10.1002/tox.20202

Links, I., Van Der Jagt, K.E., Christopher, Y., Lurvink, M., Schinkel, J., Tielemans, E., Van Hemmen, J.J., 2006. Occupational Exposure During Application and Removal of Antifouling Paints. Ann. Occup. Hyg. 51, 207-218. doi:10.1093/annhyg/mel074

Loewe, S., Muischnek, H., 1926. Combinated effects I Announcement - Implements to the problem. Naunyn. Schmiedebergs. Arch. Exp. Pathol. Pharmakol. 114, 313-326.

Ma, M., Zhu, W., Wang, Z., Witkamp, G.J., 2003. Accumulation, assimilation and growth inhibition of copper on freshwater alga (Scenedesmus subspicatus 86.81 SAG) in the presence of EDTA and fulvic acid. Aquat. Toxicol. 63, 221-228. doi:10.1016/S0166-445X(02)00179-0

Mackie, D.S., van den Berg, C.M.., Readman, J.W., 2004. Determination of pyrithione in natural waters by cathodic stripping voltammetry. Anal. Chim. Acta 511, 47-53. doi:10.1016/j.aca.2004.01.033

Maraldo, K., Dahllöf, I., 2004. Seasonal variations in the effect of zinc pyrithione and copper pyrithione on pelagic phytoplankton communities. Aquat. Toxicol. 69, 189-198. doi:10.1016/j.aquatox.2004.05.006

Mayer, P., Cuhel, R., Nyholm, N., 1997. A simple in vitro fluorescence method for biomass measurements in algal growth inhibition tests. Water Res. 31, 2525-2531. doi:10.1016/S00431354(97)00084-5

Mochida, K., Ito, K., Harino, H., Kakuno, A., Fujii, K., 2006. Acute toxicity of pyrithione antifouling biocides and joint toxicity with copper to red sea bream (Pagrus major) and toy shrimp (Heptacarpus futilirostris). Environ. Toxicol. Chem. 25, 3058-64. doi:10.1897/05-688r.1

Nimbal, C.I., Yerkes, C.N., Weston, L.A., Weller, S.C., 1996. Herbicidal Activity and Site of Action of the Natural Product Sorgoleone. Pestic. Biochem. Physiol. 54, 73-83. doi:10.1006/pest.1996.0011

Onduka, T., Mochida, K., Harino, H., Ito, K., Kakuno, A., Fujii, K., 2010. Toxicity of Metal Pyrithione Photodegradation Products to Marine Organisms with Indirect Evidence for Their Presence in Seawater. Arch. Environ. Contam. Toxicol. 58, 991-997. doi:10.1007/s00244-009-9430-8 
Patsikka, E., Aro, E., Tyystjarvi, E., 1998. Increase in the quantum yield of photoinhibition contributes to copper toxicity in vivo. Plant Physiol. 117, 619-27. doi:10.1104/pp.117.2.619

Readman, J.W., Kwong, L.L.W., Grondin, D., Bartocci, J., Villeneuve, J.P., Mee, L.D., 1993. Coastal water contamination from a triazine herbicide used in antifouling paints. Environ. Sci. Technol. 27, 1940-1942. doi:10.1021/es00046a027

Ritz, C., Streibig, J.C., 2005. Bioassay analysis using R. J. Stat. Softw. 12, 1-22. doi:10.18637/jss.v012.i05

Ritz, C., Streibig, J.C., 2014. From additivity to synergism - A modelling perspective. Synergy 1, 2229. doi:10.1016/j.synres.2014.07.010

Ritz, C., Baty, F., Streibig, J.C., Gerhard, D., 2015. Dose-Response Analysis Using R. PLoS One 10, e0146021. doi:10.1371/journal.pone.0146021

Schiff, K., Brown, J., Diehl, D., Greenstein, D., 2007. Extent and magnitude of copper contamination in marinas of the San Diego region, California, USA. Mar. Pollut. Bull. 54, 322-328. doi:10.1016/j.marpolbul.2006.10.013

Scholze, M., Boedeker, W., Faust, M., Backhaus, T., Altenburger, R., Grimme, L.H., 2001. A general best-fit method for concentration-response curves and the estimation of low-effect concentrations. Environ. Toxicol. Chem. 20, 448-457. doi:10.1002/etc.5620200228

St-Laurent, D., Blaise, C., Macquarrie, P., Scroggins, R., Trottier, B., 1992. Comparative assessment of herbicide phytotoxicity to Selenastrum capricornutum using microplate and flask bioassay procedures. Environ. Toxicol. Water Qual. 7, 35-48. doi:10.1002/tox.2530070104

Takahashi, K., 2009. Chapter 1: Release Rate of Biocides from Antifouling Paints, in: Arai, T., Harino, H., Ohji, M., Langston, W.J. (Eds.), Ecotoxicology of Antifouling Biocides. Springer Tokyo Berlin Heidelber New York, p. 22. doi:10.1007/978-4-431-85709-9

Teisseire, H., Couderchet, M., Vernet, G., 1999. Phytotoxicity of diuron alone and in combination with copper or folpet on duckweed (Lemna minor). Environ. Pollut. 106, 39-45. doi:10.1016/S02697491(99)00066-4

Thomas, K. V., 1999. Determination of the antifouling agent zinc pyrithione in water samples by copper chelate formation and high-performance liquid chromatography-atmospheric pressure chemical ionisation mass spectrometry. J. Chromatogr. A 833, 105-109. doi:10.1016/S00219673(98)01009-7 
Tubbing, D.M.J., Admiraal, W., Cleven, R.F.M.J., Iqbal, M., van de Meent, D., Verweij, W., 1994. The contribution of complexed copper to the metabolic inhibition of algae and bacteria in synthetic media and river water. Water Res. 28, 37-44. doi:10.1016/0043-1354(94)90117-1

Turner, A., Singh, N., Millard, L., 2008. Bioaccessibility and bioavailability of $\mathrm{Cu}$ and $\mathrm{Zn}$ in sediment contaminated by antifouling paint residues. Environ. Sci. Technol. 42, 8740-8746. doi:10.1021/es801923e

Turner, A., 2010. Marine pollution from antifouling paint particles. Mar. Pollut. Bull. 60, 159-171. doi:10.1016/j.marpolbul.2009.12.004

Vetere, V.F., Pérez, M.C., Romagnoli, R., Stupak, M.E., Amo, B., 1997. Solubility and toxic effect of the cuprous thiocyanate antifouling pigment on barnacle larvae. J. Coatings Technol. 69, 39-45. doi:10.1007/BF02696144

Vølund, A., 1992. Dose response surface bioassay, in: XVIth International Biometric Conference.

White, D.B., Faessel, H.M., Slocum, H.K., Khinkis, L., Greco, W.R., 2004. Nonlinear response surface and mixture experiment methodologies applied to the study of synergism. Biometrical J. 46, 5671. doi:10.1002/bimj.200210002

Yamada, H., 2006. Toxicity and preliminary risk assessment of alternative antifouling biocides to aquatic organisms. Handb. Environ. Chem. Vol. 5 Water Pollut. 5, 213-226. doi:10.1007/698-5056

Yebra, D.M., Kiil, S., Dam-Johansen, K., 2004. Antifouling technology - Past, present and future steps towards efficient and environmentally friendly antifouling coatings. Prog. Org. Coatings $50,75-$ 104. doi:10.1016/j.porgcoat.2003.06.001

Zhou, X., Okamura, H., Nagata, S., 2006. Remarkable Synergistic Effects in Antifouling Chemicals against Vibrio fischeri in a Bioluminescent Assay 52, 243-251. 


\section{Figure captions}

Figure 1: Concentration-response curves for all compounds tested singly on each species. Points (in triplicates; T. lutea: circles; S. marinoi: squares; T. suecica: triangles) correspond to the $96 \mathrm{~h}$ growth rate. Lines ( $T$. lutea: straight line; $S$. marinoi: dotted line; T.suecica: dashed line) correspond to the fitted three parameter loglogistic model with their respective $95 \%$ confidence interval in gray.

Figure 2: Illustration of an isobologram. Axes represent the concentration of the two pure substances in mixture $A$ and $B$, also represented as mixture ratios $100: 0 \%$ (A) and 0:100\% (B). The dashed lines represent mixture ratios $75: 25,50: 50$ and $25: 75 \%$ (A:B). The straight solid line identified as ' $C A$ ' is the CA isobole. The curved solid lines symbolize isoboles illustrating either antagonism (above $C A$ ) or synergism (below CA).

Figure 3: Isobolograms of binary mixtures of chemicals sharing the same mode of action. The points represent the EC50 \pm 2 standard-error, s.e. The straight solid line is the CA isobole; the dot-dashed line is the IA isobole; the curved solid line (when displayed) is the best fitting isobole model when there is a significant interaction.

Figure 4: Isobolograms of binary mixtures of chemicals with dissimilar modes of action. The points represent the EC50 \pm 2 s.e. The straight solid line is the CA isobole; the dot-dashed line is the IA isobole; the curved solid line (when displayed) is the best fitting isobole model when there is a significant interaction. 


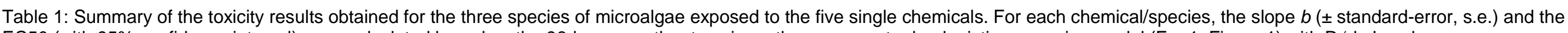
EC50 (with 95\% confidence interval) were calculated based on the 96-hour growth rate using a three-parameter log-logistic regression model (Eq. 1; Figure 1) with R 'drc' package.

\begin{tabular}{|c|c|c|c|c|c|c|c|}
\hline \multirow[b]{2}{*}{ Chemical } & \multirow[b]{2}{*}{ Mode of action } & \multicolumn{2}{|c|}{ Tisochrysis lutea } & \multicolumn{2}{|c|}{ Skeletonema marinoi } & \multicolumn{2}{|c|}{ Tetraselmis suecica } \\
\hline & & Slope $(b)$ & EC50 $\mu \mathrm{g} \mathrm{L}^{-1}( \pm 95 \% \mathrm{Cl})$ & Slope $(b)$ & $\mathrm{EC} 50 \mu \mathrm{g} \mathrm{L}^{-1}( \pm 95 \% \mathrm{Cl})$ & Slope $(b)$ & $\mathrm{EC} 50 \mu \mathrm{g} \mathrm{L}^{-1}( \pm 95 \% \mathrm{Cl})$ \\
\hline diuron & PSII & $1.86 \pm 0.13$ & $3.73 \pm 0.35$ & $3.01 \pm 0.25$ & $10.3 \pm 0.80$ & $1.62 \pm 0.03$ & $4.20 \pm 0.12$ \\
\hline irgarol & inhibitor & $1.35 \pm 0.12$ & $0.34 \pm 0.05$ & $2.98 \pm 0.15$ & $0.85 \pm 0.03$ & $1.96 \pm 0.10$ & $0.62 \pm 0.04$ \\
\hline $\mathrm{ZnPT}$ & $\begin{array}{l}\text { Membrane } \\
\text { disruption }\end{array}$ & $10.7 \pm 0.66$ & $1.25 \pm 0.07$ & $6.72 \pm 0.59$ & $1.98 \pm 0.05$ & $3.75 \pm 0.87$ & $256 \pm 18.1$ \\
\hline CuPT & & $10.3 \pm 0.60$ & $1.21 \pm 0.04$ & $10.5 \pm 0.64$ & $1.16 \pm 0.02$ & $6.71 \pm 2.40$ & $18.0 \pm 1.46$ \\
\hline $\mathrm{Cu}$ & Multiple targets & $5.16 \pm 0.67$ & $703 \pm 28.8$ & $11.2 \pm 2.60$ & $1105 \pm 48.3$ & $6.11 \pm 0.57$ & $1449 \pm 45.6$ \\
\hline
\end{tabular}




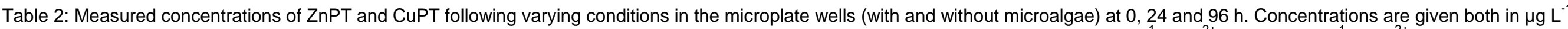

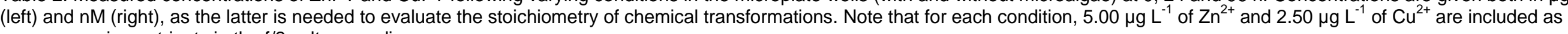
necessary micronutrients in the $\mathrm{f} / 2$ culture medium.

\begin{tabular}{|c|c|c|c|c|c|c|c|c|c|c|c|}
\hline \multicolumn{6}{|c|}{ Measured concentrations in microplates wells $\left(\mu \mathrm{g} \mathrm{L}^{-1}\right)$} & \multicolumn{6}{|c|}{ Measured concentrations in microplate wells (nM) } \\
\hline Condition & Chemical & Nominal & to & $\mathbf{t} 24$ & t96 & Condition & Chemical & Nominal & to & $\mathbf{t} 24$ & t96 \\
\hline \multirow{4}{*}{ ZnPT } & ZnPT & 10.2 & 6.50 & 2.40 & $<\mathrm{LOQ}$ & \multirow{4}{*}{ ZnPT } & ZnPT & 32.0 & 20.5 & 7.60 & $<\mathrm{LOQ}$ \\
\hline & CuPT & 0.00 & 5.80 & 2.30 & $<\mathrm{LOQ}$ & & CuPT & 0.00 & 18.3 & 7.20 & $<\mathrm{LOQ}$ \\
\hline & $\mathrm{Zn}$ & 5.00 & & & & & $\mathrm{Zn}$ & 76.5 & & & \\
\hline & $\mathrm{Cu}$ & 2.50 & & & & & $\mathrm{Cu}$ & 39.3 & & & \\
\hline \multirow{4}{*}{ CuPT } & ZnPT & 0.00 & $<\mathrm{LOQ}$ & 1.90 & $<\mathrm{LOQ}$ & \multirow{4}{*}{ CuPT } & ZnPT & 0.00 & $<\mathrm{LOQ}$ & 5.90 & $<\mathrm{LOQ}$ \\
\hline & CuPT & 9.40 & 13.7 & 2.00 & $<\mathrm{LOQ}$ & & CuPT & 29.9 & 43.4 & 6.50 & $<\mathrm{LOQ}$ \\
\hline & $\mathrm{Zn}$ & 5.00 & & & & & $\mathrm{Zn}$ & 76.5 & & & \\
\hline & $\mathrm{Cu}$ & 2.50 & & & & & $\mathrm{Cu}$ & 39.3 & & & \\
\hline \multirow{4}{*}{$\mathrm{ZnPT}+\mathrm{Cu}$} & ZnPT & 15.2 & 9.60 & 11.2 & $<\mathrm{LOQ}$ & \multirow{4}{*}{$\mathrm{ZnPT}+\mathrm{Cu}$} & ZnPT & 47.9 & 30.3 & 35.2 & $<\mathrm{LOQ}$ \\
\hline & CuPT & 0.00 & 27.7 & 17.7 & $<\mathrm{LOQ}$ & & CuPT & 0.00 & 87.8 & 56.0 & $<\mathrm{LOQ}$ \\
\hline & $\mathrm{Zn}$ & 5.00 & & & & & $\mathrm{Zn}$ & 76.5 & & & \\
\hline & $\mathrm{Cu}$ & 41.5 & & & & & $\mathrm{Cu}$ & 653 & & & \\
\hline \multirow{4}{*}{$\begin{array}{c}\mathrm{ZnPT}+\mathrm{Cu}+ \\
\quad T . \text { suecica }\end{array}$} & ZnPT & 15.2 & 9.50 & 1.50 & $<\mathrm{LOQ}$ & \multirow{4}{*}{$\begin{array}{c}\mathrm{ZnPT}+\mathrm{Cu}+ \\
\quad T . \text { suecica }\end{array}$} & ZnPT & 47.9 & 29.8 & 4.80 & $<\mathrm{LOQ}$ \\
\hline & CuPT & 0.00 & 27.6 & 2.40 & $<\mathrm{LOQ}$ & & CuPT & 0.00 & 87.2 & 7.70 & $<\mathrm{LOQ}$ \\
\hline & $\mathrm{Zn}$ & 5.00 & & & & & $\mathrm{Zn}$ & 76.5 & & & \\
\hline & $\mathrm{Cu}$ & 41.5 & & & & & $\mathrm{Cu}$ & 653 & & & \\
\hline
\end{tabular}




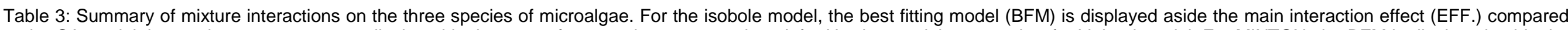

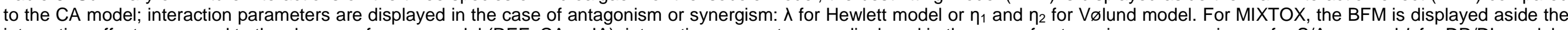

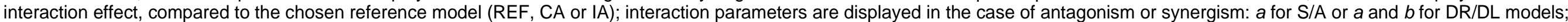

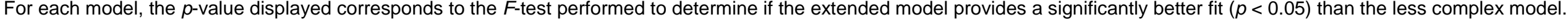

\begin{tabular}{|c|c|c|c|c|c|c|c|c|c|c|c|c|}
\hline & \multicolumn{4}{|c|}{ Tisochrysis lutea } & \multicolumn{4}{|c|}{ Skeletonema marinoi } & \multicolumn{4}{|c|}{ Tetraselmis suecica } \\
\hline & \multirow{2}{*}{\multicolumn{2}{|c|}{\begin{tabular}{cc|} 
& Isobole \\
& $\mathrm{BFM}^{(1)} / \mathrm{EFF}^{(2)}$ \\
$\Sigma \mathrm{IU}_{50: 50}$ & Int. param. \pm \\
& s.e. \\
& $p$-value
\end{tabular}}} & \multicolumn{2}{|c|}{ MIXTOX } & \multicolumn{2}{|r|}{ Isobole } & \multicolumn{2}{|c|}{ MIXTOX } & \multicolumn{2}{|r|}{ Isobole } & \multicolumn{2}{|c|}{ MIXTOX } \\
\hline & & & $\begin{array}{c}\text { Reference } \\
\text { model } \\
\text { (REF) }\end{array}$ & $\begin{array}{l}\text { BFM / EFF. } \\
\text { Int. param. } \\
p \text {-value }\end{array}$ & $\Sigma \mathrm{TU}_{50: 50}$ & $\begin{array}{l}\text { BFM / EFF. } \\
\text { Int. param. } \pm \\
\text { s.e. } \\
p \text {-value }\end{array}$ & $\begin{array}{l}\text { Reference } \\
\text { model } \\
\text { (REF) }\end{array}$ & $\begin{array}{l}\text { BFM / EFF. } \\
\text { Int. param. } \\
p \text {-value }\end{array}$ & $\Sigma \mathrm{TU}_{50: 50}$ & $\begin{array}{l}\text { BFM / EFF. } \\
\text { Int. param. } \pm \\
\text { s.e. } \\
p \text {-value }\end{array}$ & $\begin{array}{l}\text { Reference } \\
\text { model } \\
\text { (REF) }\end{array}$ & $\begin{array}{l}\text { BFM / EFF. } \\
\text { Int. param. } \\
p \text {-value }\end{array}$ \\
\hline Similar $\mathrm{MoA}^{(3)}$ & & & & & & Hewlett / SYN. & & S/A / SYN. & & Hewlett / SYN. & & DL / SYN. \\
\hline diuron:irgarol & $\begin{array}{c}1.01 \pm \\
0.08\end{array}$ & CA / ADD. & CA & CA / ADD. & $\begin{array}{c}0.92 \pm \\
0.04\end{array}$ & $\begin{array}{c}\lambda=1.09 \pm 0.042 \\
p=0.03\end{array}$ & CA & $\begin{array}{l}a=-0.26 \\
p=0.03\end{array}$ & $\begin{array}{l}0.79 \pm \\
0.05\end{array}$ & $\lambda=1.24 \pm 0.035$ & CA & $\begin{array}{c}a=-0.25 \\
b_{\mathrm{DL}}=-1.87 \\
p=0.002\end{array}$ \\
\hline ZnPT:CuPT & $\begin{array}{c}0.94 \pm \\
0.05\end{array}$ & CA / ADD. & CA & CA / ADD. & $\begin{array}{l}1.15 \pm \\
0.03\end{array}$ & $\begin{array}{c}\text { Hewlett / ANT. } \\
\begin{array}{c}\lambda=0.52 \pm 0.012 \\
p<10^{-3}\end{array}\end{array}$ & CA & 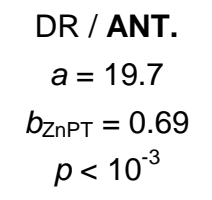 & $\begin{array}{c}0.81 \pm \\
0.57\end{array}$ & $\begin{array}{c}\text { Hewlett / SYN. } \\
\begin{array}{c}\lambda=1.14 \pm 0.076 \\
p=0.04\end{array}\end{array}$ & CA & $\begin{array}{c}\text { DR / SYN. } \\
\begin{array}{c}a=-0.90 \\
b_{\mathrm{ZnPT}}=1.25 \\
p=0.003\end{array}\end{array}$ \\
\hline Dissimilar MoA & & Vølund / ANT. & & DR / ANT. & & Vølund / ANT. & & DR / ANT. & & Vølund / ANT. & & DR / ANT. \\
\hline diuron:Cu & $\begin{array}{c}1.95 \pm \\
0.05\end{array}$ & $\begin{array}{c}\eta_{1}=1.12 \pm 0.14 \\
\eta_{2}=4.42 \pm 1.09 \\
p<10^{-3}\end{array}$ & IA & $\begin{array}{c}a=8.86 \\
b_{\text {diuron }}=-11.5 \\
p<10^{-3}\end{array}$ & $\begin{array}{c}1.15 \pm \\
0.04\end{array}$ & $\begin{array}{c}\eta_{1}=2.49 \pm 0.54 \\
\eta_{2}=0.44 \pm 0.13 \\
p<10^{-3}\end{array}$ & CA & $\begin{array}{c}a=1.73 \\
b_{\text {diuron }}=-2.50 \\
p<10^{-3}\end{array}$ & $\begin{array}{c}1.47 \pm \\
0.14\end{array}$ & $\begin{aligned} \eta_{1} & =0.65 \pm 0.11 \\
\eta_{2} & =4.10 \pm 0.74 \\
p & =1.07 \times 10^{-3}\end{aligned}$ & IA & $\begin{array}{c}a=2.58 \\
b_{\text {diuron }}=-4.22 \\
p<10^{-3}\end{array}$ \\
\hline irgarol:Cu & $\begin{array}{l}1.95 \pm \\
0.08\end{array}$ & $\begin{array}{c}\text { Vølund } / \text { ANT. } \\
\begin{array}{c}\eta_{1}=1.17 \pm 0.15 \\
\eta_{2}=4.01 \pm 0.86 \\
p<10^{-3}\end{array}\end{array}$ & IA & $\begin{array}{c}\text { DR / ANT. } \\
\begin{array}{c}a=8.04 \\
b_{\text {irgarol }}=-10.3 \\
p<10^{-3}\end{array}\end{array}$ & $\begin{array}{l}1.03 \pm \\
0.05\end{array}$ & CA / ADD. & CA & CA / ADD. & $\begin{array}{l}1.53 \pm \\
0.07\end{array}$ & $\begin{array}{c}\text { Hewlett / ANT. } \\
\begin{array}{c}\lambda=0.22 \pm 0.093 \\
p<10^{-3}\end{array}\end{array}$ & IA & 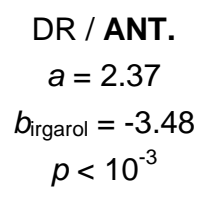 \\
\hline diuron:ZnPT & $\begin{array}{l}1.25 \pm \\
0.09\end{array}$ & $\begin{array}{c}\text { Hewlett / ANT. } \\
\begin{array}{c}\lambda=0.64 \pm 0.06 \\
p<10^{-3}\end{array}\end{array}$ & IA & $\begin{array}{c}\mathrm{DL} / \mathbf{S Y N} . \\
a=-0.01 \\
b_{\mathrm{DL}}=-275 \\
p<10^{-3}\end{array}$ & $\begin{array}{c}0.98 \pm \\
0.02\end{array}$ & CA / ADD. & CA & CA / ADD. & $\begin{array}{l}1.08 \pm \\
0.08\end{array}$ & $\begin{array}{c}\text { Hewlett / ANT. } \\
\lambda=0.74 \pm 0.069 \\
p<10^{-3}\end{array}$ & CA & $\begin{array}{c}\text { DL / ANT. } \\
a=0.39 \\
b_{\mathrm{DL}}=-1.69 \\
p=0,002\end{array}$ \\
\hline Cu:ZnPT & $\begin{array}{c}2.20 \pm \\
0.03\end{array}$ & $\begin{array}{l}\text { Hewlett / ANT. } \\
\begin{array}{l}\lambda=4.50 \times 10^{-3} \\
\pm 2.90 \times 10^{-5}\end{array}\end{array}$ & IA & $\begin{array}{c}\text { DR / SYN. } \\
a=-9.30 \\
b_{\mathrm{Cu}}=16.3\end{array}$ & $\begin{array}{c}2.43 \pm \\
0.25\end{array}$ & $\begin{array}{l}\text { Hewlett / ANT. } \\
\begin{array}{c}\lambda=4.80 \times 10^{-3} \\
\pm 3.40 \times 10^{-5}\end{array}\end{array}$ & IA & $\begin{array}{c}\text { DR / SYN. } \\
a=-1.99 \\
b_{\mathrm{Cu}}=4.93\end{array}$ & $\begin{array}{l}0.16 \pm \\
0.004\end{array}$ & $\begin{array}{l}\text { Hewlett / SYN. } \\
\begin{array}{c}\lambda=3.93 \pm 0.15 \\
p<10^{-3}\end{array}\end{array}$ & CA & $\begin{array}{l}\text { DL / SYN. } \\
a=-10.70 \\
b_{\mathrm{Cu}}=0.39\end{array}$ \\
\hline & & $p<10^{-3}$ & & $p<10^{-3}$ & & $p<10^{-3}$ & & $p<10^{-3}$ & & & & $p<10^{-3}$ \\
\hline
\end{tabular}


(1) BFM: Best fitting model, either a reference model (CA or IA) or a more complex model, Hewlett or S/A (one interaction parameter), Vølund or DR/DL (two interaction parameters).

(2) EFF.: Main interaction effect retained for the mixture, either additivity (ADD.), antagonism (ANT.) or synergism (SYN.).

(3) MoA: Mode of action. 

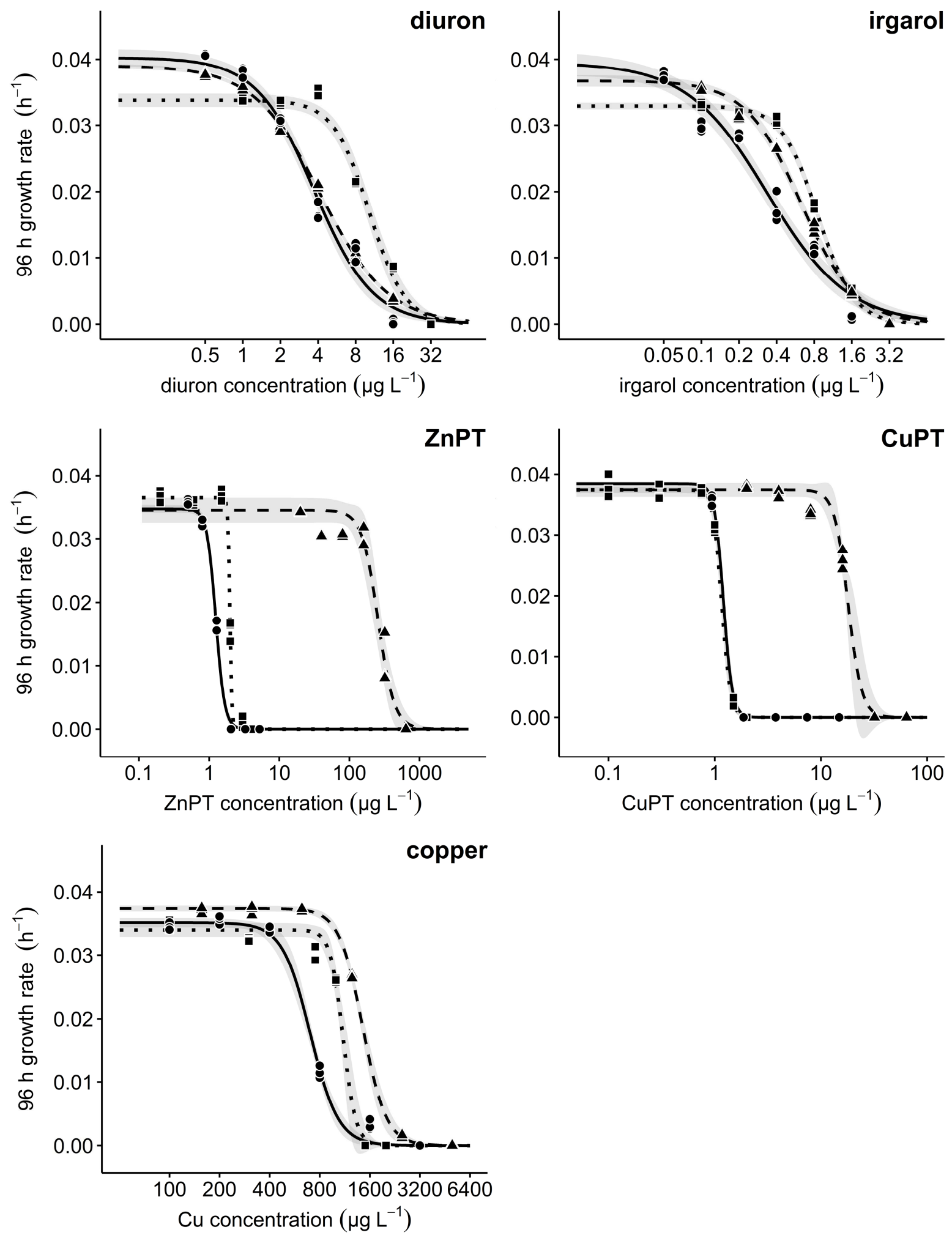


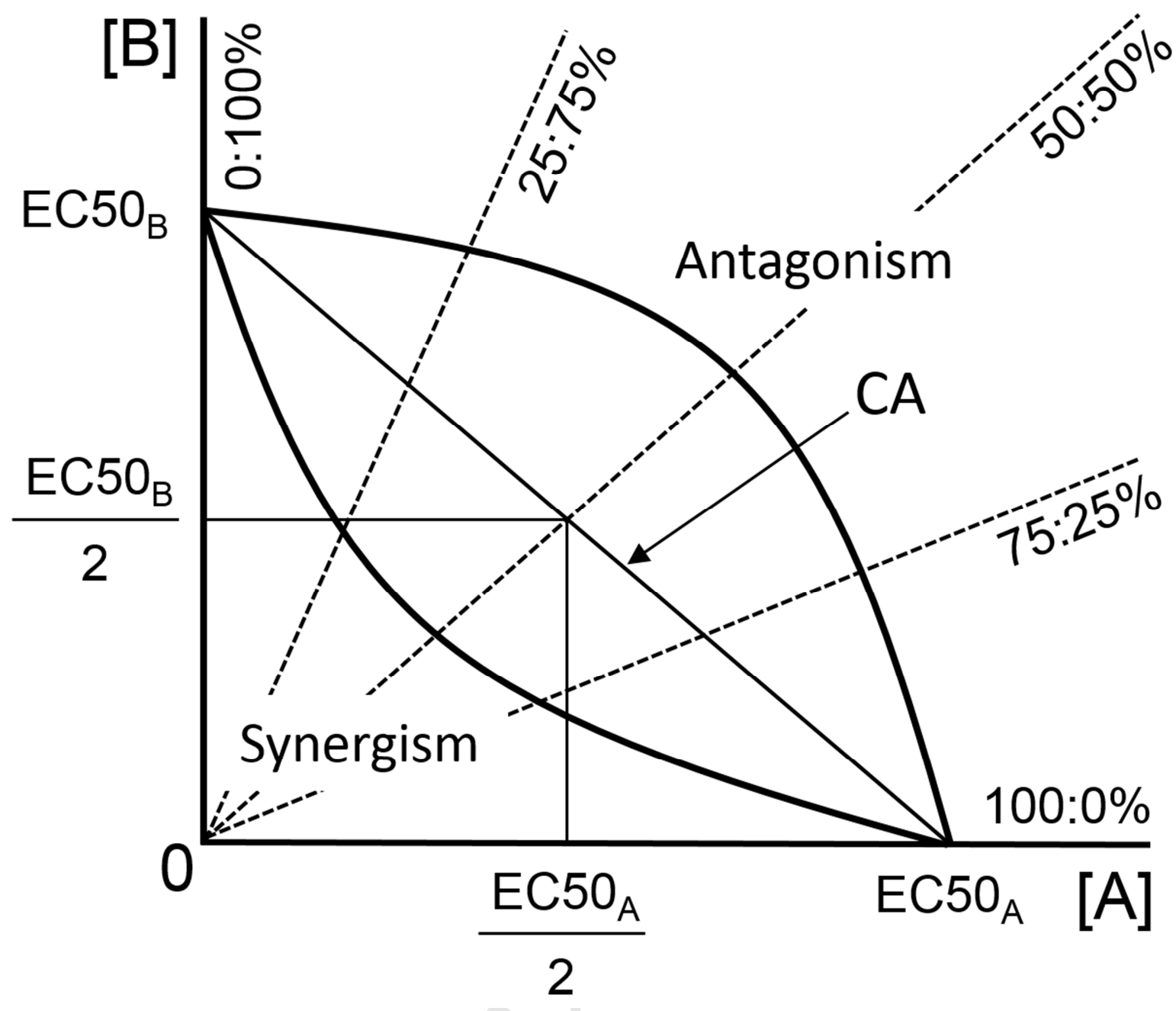



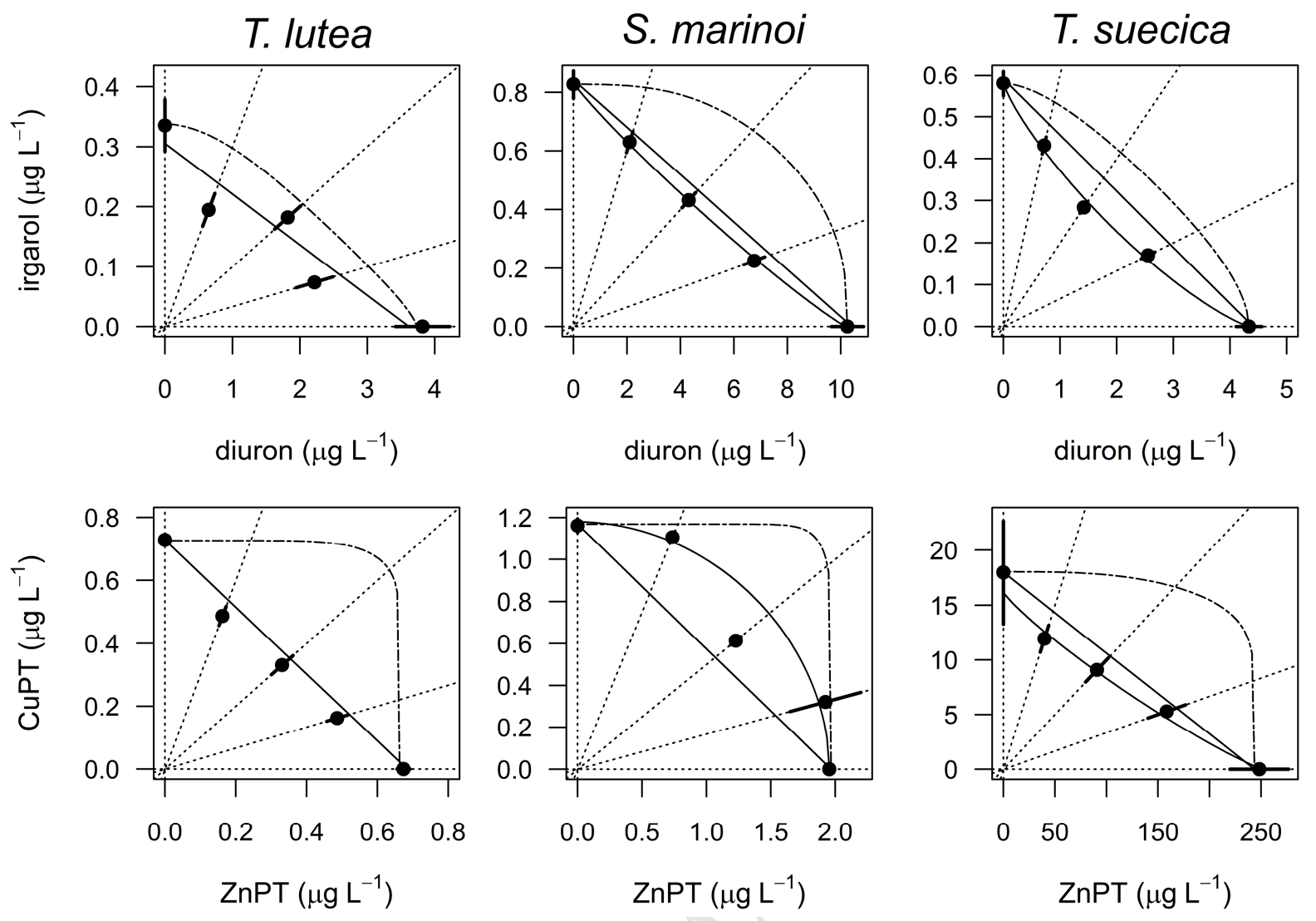

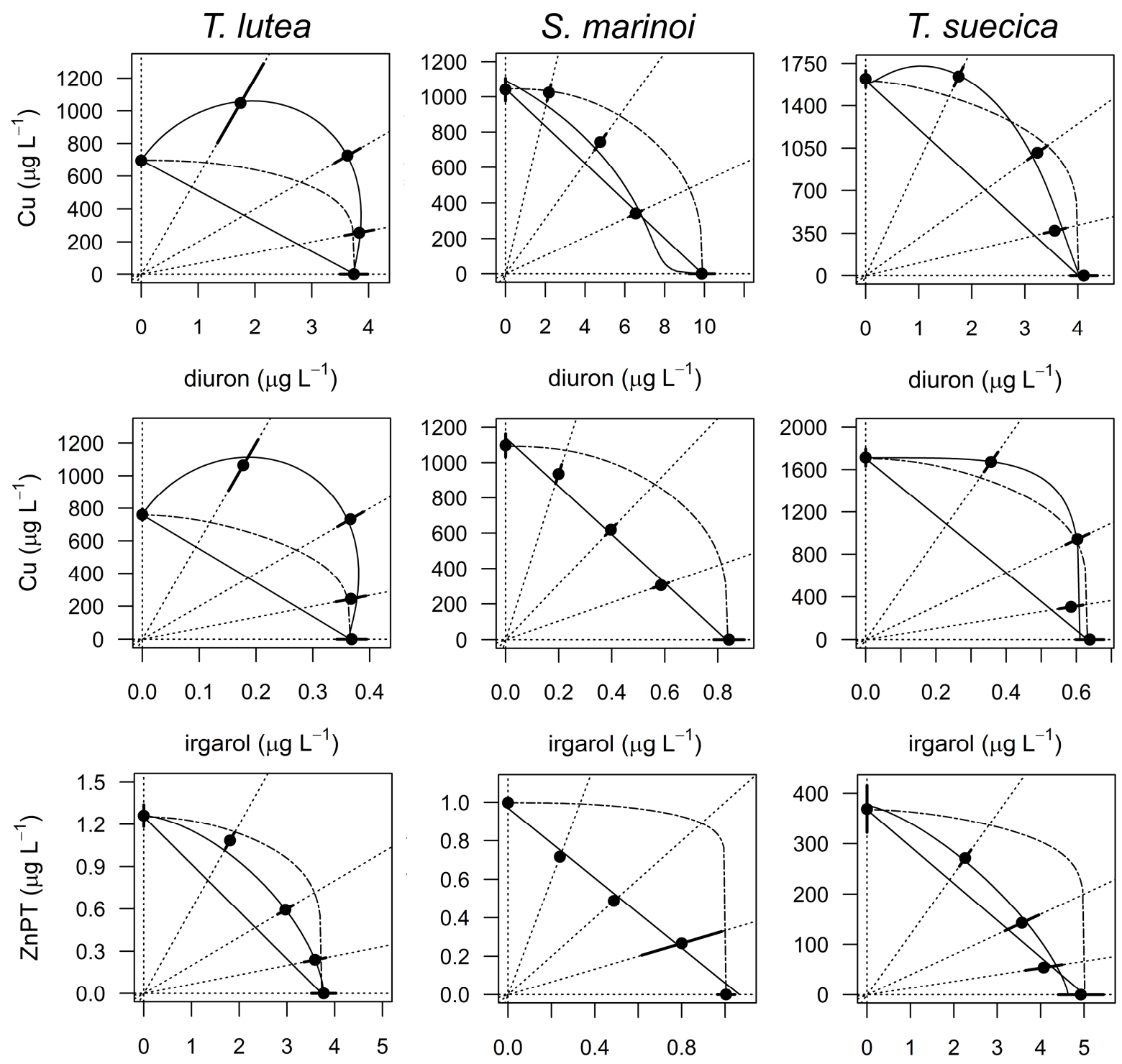

diuron $\left(\mu \mathrm{g} \mathrm{L}^{-1}\right)$

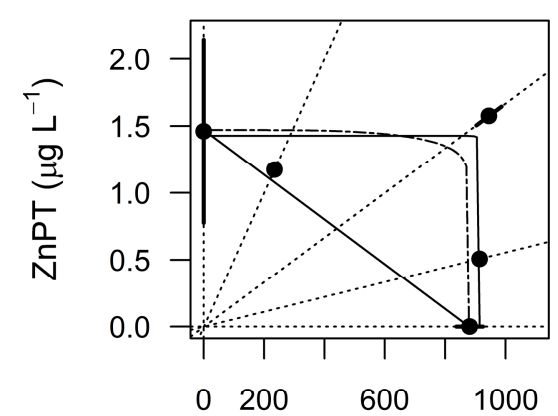

$\mathrm{Cu}\left(\mu \mathrm{g} \mathrm{L}^{-1}\right)$
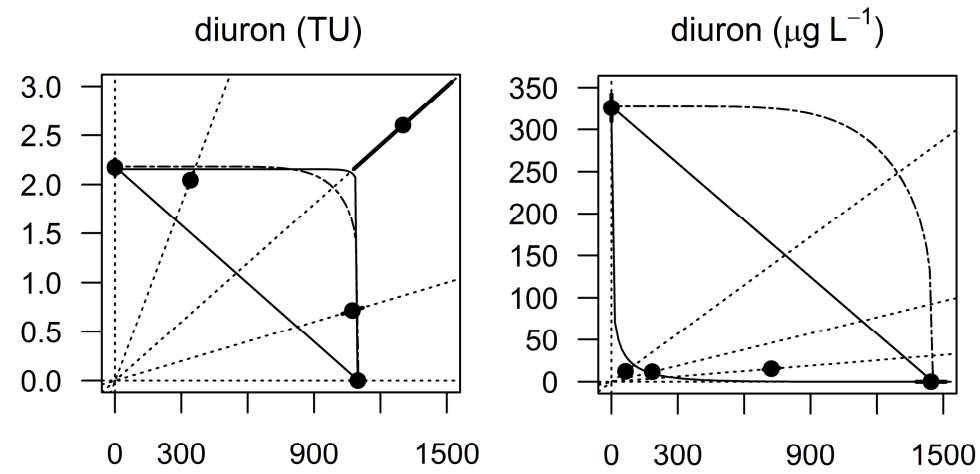

$\mathrm{Cu}\left(\mu \mathrm{g} \mathrm{L}^{-1}\right)$

$\mathrm{Cu}\left(\mu \mathrm{g} \mathrm{L}^{-1}\right)$ 